\title{
LOS PAISAJES DEL VIÑEDO EN CASTILLA Y LEÓN: TRADICIÓN, RENOVACIÓN Y CONSOLIDACIÓN
}

\author{
Fernando MOLINERO HERNANDO \\ Departamento de Geografía -Universidad de Valladolid
}

Recibido: 25/02/2011

Aceptado: 05/07/2011

RESUMEN: El viñedo de Castilla y León ha conocido una coyuntura muy favorable desde hace unos veinte años. Esa circunstancia ha sido aprovechada para invertir, modernizar y construir nuevos pagos vitícolas y nuevas bodegas. Pero el dinamismo, que ha sido general en las comarcas vitícolas, ha sido desigual en los viticultores, de modo que los más mayores o carentes de iniciativas empresariales se han acomodado a los nuevos tiempos con pequeños cambios, pero sin dar el paso a la construcción de una nueva bodega.

Estas circunstancias se reflejan perfectamente en el paisaje, pues tanto en el eje del Duero como en Rueda, y en menor medida en otras comarcas, se han levantado las típicas haciendas vitícolas, de mayor o menor superficie, con sus bodegas y dependencias anejas, que han sido secundadas por bodegas de talla familiar, con viñas más o menos dispersas en pagos vitícolas, y que han permitido también que los viticultores integrados en cooperativas renovasen sus viñedos o se mantuvieran operativos al calor de las coyunturas.

Este artículo caracteriza y analiza los paisajes vitícolas de Castilla y León, con los rasgos que les presta el tipo de explotación, por un lado, y el medio ecológico en el que se desarrollan, por otro.

PALABRAS CLAVE: Viñedo, Castilla y León, hacienda vitícola, bodega familiar, viñedo de pago.

THE LANDSCAPES OF VINEYARDS IN CASTILLA Y LEÓN: TRADITION, RENEWAL AND CONSOLIDATION

ABSTRACT: The vineyards of Castilla y León have experienced a very favorable situation during the last twenty years. That fact has been used to invest, modernize and build new vineyards and new wineries. But the dynamism, that has been general in the vineyards regions, has been uneven among the farmers involved in the viticulture, so that the elderly or lacking in entrepreneurial initiatives have adapted to modern times with small changes, but without giving way to the construction of a new wine cellar.

These circumstances are reflected perfectly in the landscape, for both the axe of Duero and Rueda, and to a lesser extent in other counties, that have raised the typical wine-growing estates, with larger or smaller area, with its wineries and attached units. This big wineries have been followed by family size ones, with more or less scattered vineyards in wine specialized fields, and have also allowed that growers integrated in cooperatives wineries, renew their vineyards or keep themselves operating under the favorable context. 
This paper characterizes and analyzes the wine landscape of Castilla y Leon, with the features provided by the kind of agricultural holding on the one hand, and the ecological environment in which they operate, on the other.

KEY WORDS: Vineyard, Castilla y León, Viticulture holding, family winery, vineyard fields.

\section{INTRODUCCIÓN: NUEVOS TIEMPOS, NUEVOS VIÑEDOS Y NUEVOS PAISAJES EN CASTILLA Y LEÓN}

Los paisajes del viñedo en Castilla y León tienen un gran interés territorial, agrario, económico y social, no tanto como en el pasado, pero sí mucho más que hace medio siglo. En efecto, el viñedo, cultivo mediterráneo que superó sus límites ecológicos originarios llegando a ocupar tierras de condiciones naturales críticas, ha sorteado la gran crisis de los años 1955 a 1985 con un nuevo impulso colonizador, asentándose tanto en tierras favorables como en otras consideradas antes desfavorables.

La pujanza actual de los viñedos se ha acompañado de una pujanza parecida de las bodegas, con un carácter completamente distinto al tradicional. Es así como un cultivo que ocupó grandes extensiones de terreno en el pasado, casi por todos los pagos, hoy se ha concentrado principalmente en las áreas de denominación de origen, con una nueva dinámica, con un carácter más empresarial que el de antaño y con unos resultados económicos y sociales muy mejorados con respecto al pasado.

Y esa especialización, concentración y renovación ha dado por resultado, también, unos nuevos paisajes de la vid y el vino. Frente al viñedo de consumo local y comarcal tradicional, se han levantado los viñedos de consumo regional, nacional y mundial. Frente al carácter diminuto de las parcelas, a menudo orientadas casi a una economía de subsistencia, o, al menos, de autoconsumo, se levantan los grandes pagos vitícolas, producto de la unificación de numerosas parcelas preexistentes. Frente a las vides en vaso, absolutamente dominantes en el pasado, hoy se han extendido las viñas en espaldera. Frente al casi generalizado vino "clarete", hoy se han consagrado los blancos y los tintos. Frente a los barrios de bodegas excavadas en terrenos pendientes o en los sótanos de las casas, hoy se levantan edificios señeros, dispersos, organizados al estilo de los "chateaux" bordeleses, que apenas condicen con las construcciones relacionadas con la vid y el vino tradicionales.

Son los nuevos tiempos y los nuevos paisajes, cada vez más valorados por la sociedad y no sólo por un creciente aprecio social y personal del paisaje agrario, y del paisaje en general, sino porque el viñedo crea enclaves y pagos de paisaje verde cuando todo el terreno circundante es pardo, amarillo y 
marcescente; el viñedo tiñe de exuberancia los campos vacíos que lo rodean, introduce un ecotopo singular lleno de densidad vegetal, de vida animal y de diversidad cromática.

Castilla y León, que, salvando algunas excepciones, no tuvo viñedos afamados hasta fechas relativamente recientes, es hoy cuna de grandes vinos del mundo, y con sus vinos, y con sus bodegas, es también tierra de diversos, variados y cambiantes paisajes del vino, que son cada vez más valorados por todos los que participan en el creciente turismo en torno al vino.

En consecuencia, nuestro objetivo es localizar, cuantificar y valorar la superficie y la dinámica del viñedo regional, como paso previo a su caracterización y tipificación, lo que nos permitirá hacer un análisis y valoración de los paisajes del viñedo en Castilla y León

\section{EVOLUCIÓN RECIENTE Y SITUACIÓN ACTUAL DEL VI- ÑEDO EN CASTILLA Y LEÓN}

El cultivo de la vid, ancestral en las tierras templadas de Europa, ha absorbido gran cantidad de trabajo y esfuerzo de personas y de generaciones de viticultores. Normalmente, no se trabajaba como cultivo único, sino que complementaba a aprovechamientos herbáceos considerados más importantes, como los cereales, especialmente el trigo -el cereal rey-. Trigo y vino constituían la base de la alimentación humana y a su obtención se destinaba la mayor proporción del labrantío. El refrán de que "con pan y vino se anda el camino" tenía su justo reflejo en la vasta extensión ocupada por campos de trigo y vides. Y, aunque se distribuían por todos los pagos, a veces se concentraban selectivamente, dejando para viña los terrenos más flojos, más arenosos, más filtrantes, donde la corta raíz del cereal no podía prolongarse lo suficiente como para absorber los nutrientes y el agua profundos. Sin embargo, también era frecuente que cada familia destinase a viñas una parte de sus tierras, que aparecían, así, como enclaves dispersos que daban colorido y salpicaban de verdor a los rastrojos y barbechos abrasados por los soles del estío mediterráneo. Pero este panorama tenía sus días contados a mediados del siglo $\mathrm{XX}$.

\section{La decadencia vitícola y vinícola asociada al éxodo rural}

Esta distribución de campos de trigo y viñas, inorgánica, un tanto aleatoria, aunque generalmente las viñas se asentaban en las peores tierras, se mantuvo durante largos siglos hasta fechas recientes. Las exigencias de la modernización agrícola acabaron con esa organización: las viñas quedaron diezmadas en muy poco tiempo, entre 1960 y 1980, cuando, al intenso éxodo rural se le sumó la carestía de la mano de obra agraria y la depreciación del vino. Esas 
circunstancias unidas motivaron que la viticultura se hundiera, que sólo los mayores de edad o los amantes de este cultivo mantuvieran un hilo de esperanza, que permitió la permanencia del viñedo. Eran tiempos difíciles, pues el vino se vendía barato y mal, las bodegas cooperativas estaban llenas de caldo, los trabajos de la vid eran numerosos y ya no quedaban obreros para cubrirlos a un precio decente, por lo que desde mediados de los años 1970 hasta mediados de los 1980 se produjo un drástico retroceso del viñedo y durante los otoños de ese decenio se podían contemplar en las eras de los pueblos los montones de troncos de cepas que se utilizaban como combustible de las glorias. Las tierras de vides se sustituían por campos de cereal, más fácilmente mecanizable y con unos rendimientos económicos parejos a los de la vid en aquel momento. De hecho, la superficie vitícola de Castilla y León pasó de casi 104.000 ha en 1950 a las 82.837 en 1985 y a 69.538 en 1996, ya a comienzos de la recuperación (MAPA, Anuarios de Estadística Agraria). Tal como se ve en la FIGURA 1 y 2, la reducción de las manchas de viñedo entre 1960 (mapa de Huetz) y 2006, basado en el Corine Land Cover 2006 (en adelante CLC 2006), ha sido drástica y aún no ha acabado en las tierras menos favorecidas.

Figuras 1 y 2. Extensión del viñedo de Castilla y León en 1960 (izda) y en 2006 (derecha)

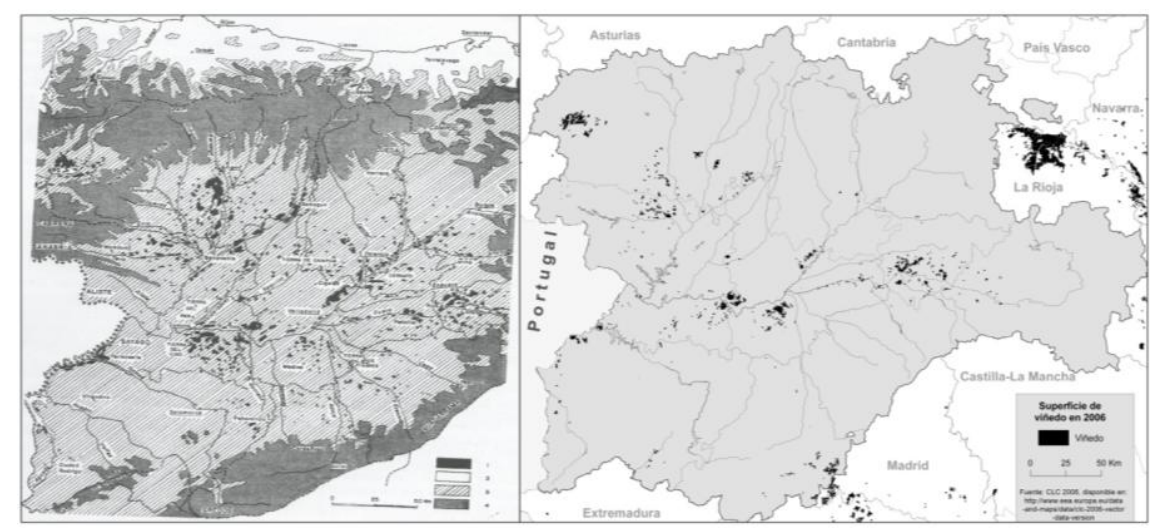

Izquierda: extensión del viñedo del Duero en 1960 (según Huetz): 1-Viñedos; 2-Altitud inferior a 500 m; 3-Altitud entre 500 y 1.000 m.; 4-Altitud superior a 1.000 m. (en línea discontínua, límites provinciales). Derecha: extensión del viñedo en 2006, según CLC2006 en Castilla y León y CCAA limitrofes.

El paisaje del viñedo quedaba constreñido y languideciente, pues no sólo se arrancaban las viñas, sino que se abandonaban los elementos tradicionales de la vinificación. Así, las bodegas que ocupaban los sótanos de las casas se cegaron o se abandonaron, por su peligrosidad; las bodegas subterráneas ex- 
cavadas en los cerros de los alrededores de los pueblos dejaron de recibir vino y fueron abandonándose hasta su ruina o, en los mejores casos, se transformaron en merenderos, que no respetaron el estilo constructivo original; los lagares comunales o privados se dejaron caer, y todo un mundo de edificios, utensilios, aperos, herramientas y artesanos relacionados con las labores de la vid y con el proceso de obtención del vino, fue desapareciendo.

La entrada en la CEE trajo un poco de alegría a los viticultores: el precio del vino subió, las bodegas vendieron sus caldos merced a compras masivas de agentes extranjeros que adquirían a buen precio los vinos españoles de pasto para destinarlos a la destilación y cubrir así con la Entrega Vínica Obligatoria en el solar ibérico en vez de hacerlo en Francia o en Italia. Los escasos viticultores que apostaron por mantener sus viejas viñas vieron abrirse un claro entre los nubarrones que amenazaban al cultivo. A este proceso se sumó otro hecho más importante: el aumento del nivel de vida en España y la demanda de vinos de calidad contribuyeron decisivamente a que se implantaran y cristalizaran las Denominaciones de Origen, que fueron claves en el resurgimiento y expansión de la vid y el vino.

\section{Los comienzos de la recuperación a partir de las Denominaciones de Origen Protegidas (DOP)}

Si las viñas se arrancaban debido a su escasa rentabilidad, a principios de la década de 1980 comenzaron a cambiar las circunstancias. Fue en ese año cuando se aprobó la primera Denominación de Origen de Castilla y León: la DO "Rueda", promovida desde fuera, por el Marqués de Riscal, para la obtención de vinos blancos. A pesar de los titubeos, la figura de calidad se consolidó y no sólo cristalizó, sino que sirvió de ejemplo a otros viticultores ribereños que desde Burgos se empeñaron en aprobar una DO para la ribera del Duero, hecho que se consiguió en 1982. Sin embargo, este proceso, destacable y trascendental, no se percibió así, sino que numerosísimos viticultores continuaron descepando y arrancando viñas y transformándolas en campos de cereal, pues el vino tenía poca estima y su consumo continuaba bajando. De este modo, se pasó de consumos del orden de 46,6 1/persona y año en 1987 a 32,5 en 1992, a 28,3 en 2003 y a 18,6 en 2008 y hasta 10,1 en $2009^{1}$; sin embargo, hay un matiz importante y es que el consumo de vinos de calidad con DOP estaba y está aumentando y en 2008 alcanzaba en España una media de 8,84 1/hab/año, habiéndose incrementado su consumo un

\footnotetext{
${ }^{1}$ Pero este dato de 2009 no es comparable, por cambio de método. En efecto, el Panel Alimentario del MARM da esa cifra (p. 26 del documento Consumo Alimentario en España), consultable en: http://www.mapa.es/alimentacion/pags/consumo/año_movil_jul08_jun09/ año_movil_jul08_jun09.pdf
} 
$8 \%$ con respecto a 2007, según las fichas de consumo alimentario del Ministerio de Agricultura (actual MARM), en tanto que el conjunto de los vinos caía en la misma proporción, y ésa es la clave del auge de los viñedos y vinos del Duero y de otras regiones vitícolas ibéricas, ya que incluso durante la crisis ha continuado aumentando la demanda de vinos de calidad (vinos de calidad producidos en regiones determinadas, -v.c.p.r.d-), por más que haya caído la de cavas y espumosos.

Cuadro 1: Superficie de viñedo en las distintas comarcas vitivinícolas de CyL en 1985 y 2008

\begin{tabular}{|c|c|c|c|c|c|c|c|c|}
\hline \multirow{2}{*}{ DOP y otras* } & \multicolumn{4}{|c|}{ Viñedo (ha en 1985 y 2008) } & \multicolumn{4}{|c|}{ Cultivos (ha en 2008) } \\
\hline & $a$ & $b$ & $c$ & $d$ & $e$ & $f$ & $g$ & $h$ \\
\hline DOP Rueda & 7.352 & 9.425 & 742 & 10.167 & 51.638 & 180.409 & 5,6 & 264.373 \\
\hline DOP Ribera del Duero & 12.121 & 19.975 & 646 & 20.621 & 24.361 & 188.698 & 10,9 & 344.104 \\
\hline DOP Toro & 4.529 & 5.353 & 389 & 5.742 & 17.167 & 49.139 & 11,7 & 70.844 \\
\hline DOP Cigales & 2.489 & 3.405 & 32 & 3.437 & 5.145 & 36.882 & 9,3 & 55.668 \\
\hline DOP Arribes & 5.776 & 3.150 & 0 & 3.150 & 129 & 25.207 & 12,5 & 162.297 \\
\hline DOP T.V. de Zamora & 4.681 & 3.295 & 113 & 3.408 & 24.441 & 125.553 & 2,7 & 187.874 \\
\hline DOP Tierra de León & 16.129 & 6.037 & 48 & 6.085 & 69.063 & 202.303 & 3,0 & 298.472 \\
\hline DOP Bierzo & 8.162 & 5.250 & 0 & 5.250 & 6.496 & 7.773 & 67,5 & 152.903 \\
\hline DOP Arlanza & 832 & 509 & 0 & 509 & 911 & 20.718 & 2,5 & 37.909 \\
\hline V.C. V. de Benavente & 5.023 & 2.836 & 1 & 2.837 & 21.383 & 57.638 & 4,9 & 140.606 \\
\hline V.C. Valtiendas & 738 & 411 & 0 & 411 & 1.081 & 15.303 & 2,7 & 28.735 \\
\hline Cebreros & 7.694 & 2.873 & 0 & 2.873 & 2.603 & 4.442 & 64,7 & 123.229 \\
\hline Sierra de Salamanca & 1.818 & 715 & 0 & 715 & 84 & 2.014 & 35,5 & 22.117 \\
\hline Otros municipios & 15.493 & 5.654 & 264 & 5.918 & 126.392 & 940.083 & 0,6 & 2.019 .100 \\
\hline Total general & 92.837 & 68.888 & 2.235 & 71.123 & 350.894 & 1.856 .162 & 3,8 & 3.908 .231 \\
\hline
\end{tabular}

* Los datos de hectáreas totales corresponden a las existentes en los municipios de las respectivas $D O$, pero no a las que están inscritas o registradas, pues no todos los viticultores están acogidos a las $D O$

$a$, Viñedo total en 1985; b, Viñedo de secano 2008; c, Viñedo de regadío 2008; d, Viñedo total en 2008; e, Total de tierras regadas; $f$, Tierras arables más cultivos permanentes; $g$, \% viñedo/tierras cultivo; $h$, Superficie municipal total (ha, 2008)

FuENTE: Consejería de Agricultura de la Junta de C. y L., Documentos $1 T 1985$ y 2008

Hasta finales de la década de 1980 no empezó a notarse la nueva coyuntura, pero, aunque tardó en consolidarse, lo hizo y con fuerza, si bien de una manera diferenciada. Así, los viñedos de Rueda, los primeros en consagrarse, tardaron en expandirse y, a pesar de su gran salto de los años 1980 y 1990, mantuvieron cierto estancamiento posterior hasta su nueva fase expansiva, en la que se encuentran. Sin embargo, los grandes viñedos de Castilla y León han sido los de uva tinta de La Ribera, que no han dejado de crecer y que, a pesar de la crisis, están llamados a ocupar una mayor expansión y papel en el mapa mundial del vino. La de DO Toro (en 1987) siguió el ejemplo de La Ribera y podríamos decir que sigue los mismos pasos. El Bierzo, ya en 1989, fue la siguiente DO regional, aunque más titubeante. Dos años más tarde, se aprobó la DO Cigales, con poca entidad y con mucho camino por recorrer y, aunque no ha tenido el éxito de las tres anteriores, reúne condiciones para conseguirlo. Finalmente, como nadie quería quedarse excluido de esta fiesta, en el año 2007 se aprobaron otras tres DOP: Los Arribes, Ar- 
lanza, y Vino de la Tierra de León, quedando otras comarcas a la expectativa, como Valtiendas y los Valles de Benavente, o como Cebreros y la Sierra de Salamanca.

Este proceso no es casual ni homogéneo, pues la valoración del vino ha sido desigual; de hecho, en las comarcas tradicionales todavía se continúa con el arranque de viñas, como lo pone de manifiesto el cuadro 1, en el que se ve la evolución de la superficie vitícola entre 1985 y 2008 en las áreas protegidas y en el resto, apreciándose nítidamente que aún se está perdiendo superficie vitícola regional, por más que en La Ribera, Toro o Rueda se haya incrementado sustancialmente $\mathrm{y}$, junto al viñedo, están aumentando de una manera más llamativa aun las bodegas, que se han erigido en el pilar del nuevo desarrollo rural de la comarca.

\section{Papel de viñedos y bodegas en la diversificación y el desarrollo ru- ral}

El proceso de crecimiento de las bodegas del Duero ha sido espectacular desde los años 1980 hasta hoy y no ha terminado, con la particularidad de que las nuevas bodegas, bien de talla familiar, o bien de dimensiones mucho mayores, están dando lugar a una nueva ocupación y organización territorial, muy distinta a la anterior y con una extraordinaria capacidad económica y de transformación espacial y paisajística. Las nuevas bodegas mercantiles, en contra de las tradicionales de autoconsumo, no se agrupan en barrios en torno a los núcleos de poblamiento, ni se construyen sobre las faldas de un cerro elevado para aprovechar mejor la sequedad de los terrenos más altos, sino que se distribuyen dispersas, sembradas en el campo, dominando pagos vitícolas organizados en su entorno, al estilo de los cortijos andaluces o de los "chateaux" franceses. Bodegas familiares y grandes bodegas conviven y se dan la mano en el campo y en los bordes de cada pueblo e introducen un paisaje nuevo y distinto al tradicional.

Llaman la atención no sólo por sus formas, por su entidad y por su carácter nuevo, sino también por su densidad y por su número creciente y hasta imparable, producto del gran atractivo que ejercen las áreas vitícolas con DOP, y especialmente las del Valle del Duero. Baste recordar a este respecto que ya en 2007 había 412 bodegas acogidas a las DO del Valle del Duero más Rueda (Arribes, Tierra del Vino de Zamora, Toro, Rueda, Cigales y La Ribera del Duero), cuando en los años 1980 no representaban más que una mínima fracción de las que hay ahora y prácticamente correspondían a unas decenas de bodegas cooperativas que nacieron tan sólo para evitar la quiebra de la viticultura tradicional. 
Este auge y dinamismo extraordinario de la vid y el vino en Castilla y León, está modificando el panorama agrario de las principales comarcas afectadas, de modo que puede decirse con toda propiedad que, frente a la depresión socioeconómica del rural profundo de Castilla y León, las tierras vitícolas, con sus bodegas y la crianza del vino, han introducido una dinámica rural progresiva, muy por encima de lo esperable hace tan sólo dos decenios. Es más, podríamos afirmar que las tierras del Duero, en función de sus aprovechamientos vitícolas, han entrado en el cuarto paradigma de desarrollo rural, en el que la plurifuncionalidad es una realidad, pero en el que la diversidad de funciones y actividades económicas procede del mundo del vino, tanto en su vertiente y fase vitícola como en sus aspectos industriales de transformación, cría y comercio del vino más que de otras nuevas funciones rurales. Por ello, y antes de hacer una valoración paisajística y patrimonial de los viñedos durienses, conviene hacer una tipificación previa, por cuanto no todos tienen las mismas características ni resultados.

\section{CARACTERIZACIÓN Y TIPIFICACIÓN DE LOS VIÑEDOS REGIONALES}

Las casi 72.500 ha de viñedo de Castilla y León no son la herencia de lo que fueron los vastos pagos vitícolas tradicionales, extendidos por todas las llanuras de la región y por una parte de las vertientes montañosas solanas y soleadas. De aquellas viñas queda apenas el recuerdo en la mayor parte de los pueblos y en unos pocos quedan unas pequeñas parcelas dispersas, fruto del amor al terruño y al cultivo de la vid que han tenido sus titulares, quienes apenas sobreviven a las cepas que plantaron en su juventud.

Es así como el paisaje tradicional de la vid y el vino ha desaparecido, en aras de su adaptación a la demanda y nuevas exigencias del mercado. Por ello, cuanto más éxito ha tenido una comarca menos elementos de la tradición y del patrimonio vitivinícola conserva. De entrada, podemos decir que la renovación ha sido total y que hasta el tipo de vino elaborado en las tierras del Duero ha cambiado radicalmente. Así, si los vinos tintos espesos, de mucho cuerpo y contenido tánico constituían un patrimonio de Toro, hoy han sucumbido a la demanda de vinos tintos más suaves y elegantes, moda que ha invadido todas las comarcas regionales, pese a la especialización de algunas en otro tipo de vinos, pero tanto los viñedos del Sil en el Bierzo como el resto de las comarcas vitícolas de Castilla y León se orientan preferentemente a los tintos, salvo Rueda y algunos otros rincones relictos, como veremos, de modo que el tipo de vino producido y comercializado es hoy el primer factor de diferenciación, sin olvidar la singularidad ecológica de cada comarca. 
Tal como se recoge en el mapa (FIGURA 3), las nueve denominaciones de origen de Castilla y León, más las otras dos comarcas reconocidas como vinos de calidad, representan la casi totalidad del viñedo regional, pues, en efecto, hoy no se pueden mantener viñedos comerciales sin el amparo de una figura de calidad que certifique su valor.

El vino elaborado en todas ellas es predominantemente tinto, con la salvedad del blanco de Rueda y de los minoritarios rosados en casi todas ellas. Pero el valor de los vinos tintos por un lado, y de los blancos por otro, se impone.

Figura 3. Figuras de calidad y comarcas vitícolas en Castilla y León

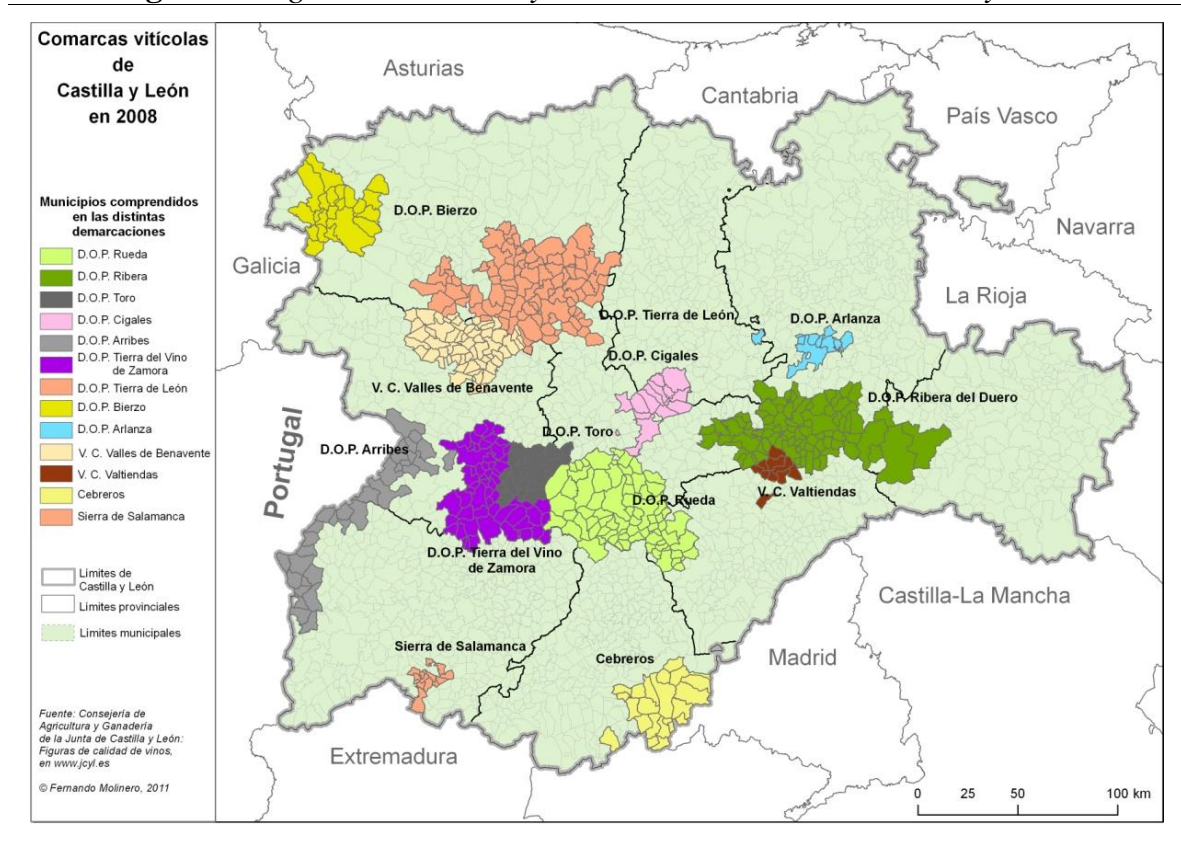

\section{La explosión de los viñedos del vino tinto de Castilla y León}

Resulta curioso comprobar cómo cambia el consumo y la demanda en cada momento histórico. Tradicionalmente, la cuenca del Duero se había especializado en los "claretes" o rosados, porque eran caldos muy adaptados al consumo tradicional, en el que el vino era considerado, además de alimento, bebida refrescante y energética. Por ello, las cepas dominantes -de Tempranillo mayoritariamente, o de Prieto Picudo y Mencía- solían ir acompañadas de otras variedades, como la blanca de Jerez Palomino, que, además de dar mucha cantidad de uva, se mezclaba, en una proporción de en torno al 10\%, con aquélla, para elaborar los afrutados y refrescantes claretes, de unos $11^{\circ}$, para 
un consumo anual generoso y de pocas exigencias. Pero esta situación cambió radicalmente cuando la demanda del mercado, prioritariamente dirigida hacia los vinos tintos, permitió descubrir las posibilidades del Tempranillo para el envejecimiento y la crianza, por su alto contenido en azúcar, en pigmentos azules o antocianos y en aromas, que dan a los vinos tintos del Duero una personalidad y singularidad de gran valor y estima gastronómicas.

\section{a) Los viñedos colonizadores y expansivos del eje del Duero}

Todo el valle del Duero, debido a esa circunstancia, probó, con éxito, la elaboración de vinos tintos, mucho más demandados y con más posibilidades de añejar y, por tanto, de multiplicar su valor económico. Sin embargo, comarcas como Rueda, que siempre fueron asiento de variedades de uva blanca, continuaron produciendo su "verdejo" como variedad de gran valor enológico, a pesar de las dificultades de su laboreo y cuidado. Pero los viñedos de Tempranillo enseñorearon los nuevos pagos vitícolas del valle del Duero, tanto en La Ribera como en Toro y en otras comarcas de menor entidad, por más que la Garnacha, la Cabernet-Sauvignon u otras variedades menores tengan presencia y hasta entidad en algunas explotaciones. Incluso Los Arribes del Duero, que siempre habían producido sus vinos a partir de la variedad autóctona Juan García, se han orientado -tal vez equivocadamente- hacia el Tempranillo.

Así, aunque los reglamentos de las respectivas DOP permiten la elaboración de vinos con variedades distintas a la Tempranillo, es esta la que se impone masivamente en el Valle del Duero, desde San Esteban de Gormaz hasta los Arribes. Sin embargo, esta situación no es nueva, puesto que ya sucedía así tradicionalmente, excepto en esta última comarca, pero estos viñedos del vino tinto han cambiado radicalmente su fisonomía y el paisaje resultante. Basta comparar una simple fotografía aérea del vuelo americano (1956) con una actual para tomar conciencia de los cambios, y hasta mutaciones, habidos en estos viñedos. El ejemplo de Las Bodegas Condado de Haza en Roa, en los confines con La Horra (Burgos), es bien expresivo al respecto (FIGURA 4). Todo el Valle del Duero ha conocido un proceso imparable de crecimiento de sus viñas y bodegas, bien como haciendas vitícolas, bien como secanos y regadíos convertidos en viñas desde su dedicación a cultivos herbáceos anterior, o bien como mantenimiento de las escasas viñas viejas y más cuidadas, todo lo contrario de lo sucedido entre los años 1970 y 1990.

En primer lugar, se perciben los cambios en el grado de concentración y densidad de los pagos vitícolas. Frente a la mayor entidad y dispersión tradicional, se ve una clara especialización y concentración actual. Frente a una malla de pequeñas parcelas, con un sinfín de lindes, ribazos, hileras de al- 
mendros, salpicadas de zarzas y con sus pequeñas casetas o chozos de labor que se repartían por todos los pagos, hoy se observa una malla de grandes parcelas y hasta de pagos que hacen del viñedo a menudo un monocultivo, organizado en grandes polígonos, ordenados y geométricos. Frente a la diversidad tradicional, la monotonía es la nota actual, frente al viñedo en copa, el viñedo en espaldera; frente a los numerosos chozos de piedra, la silueta dominante y señera de las bodegas. La comparación de las fotos es bien expresiva al respecto.

Figura 4. Pagos vitícolas de las bodegas Condado de Haza, entre Roa y La Horra, en 1956 (izquierda) y en 2007 (derecha)

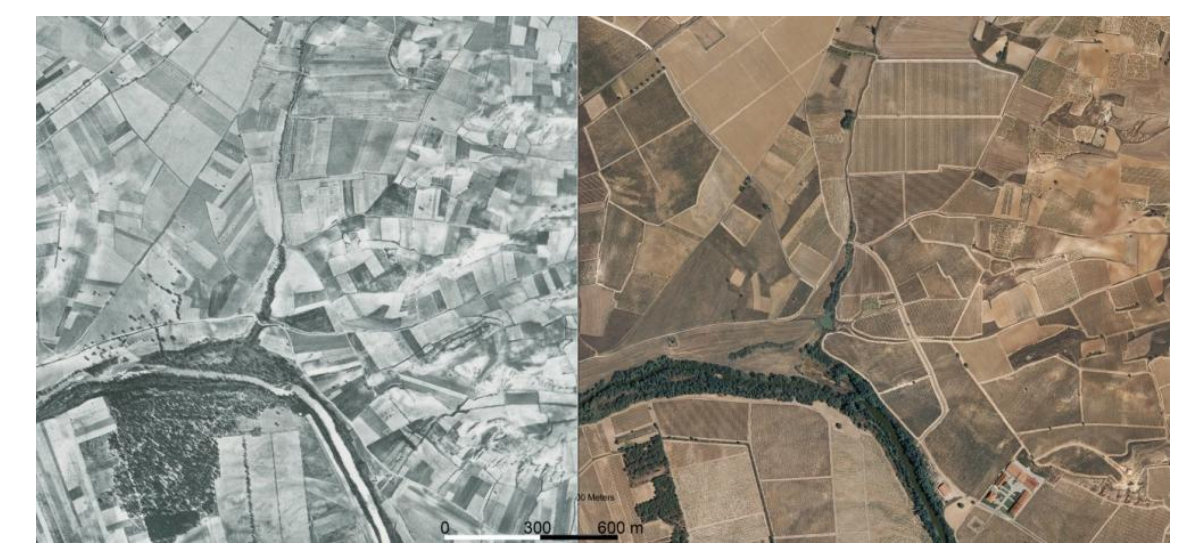

Aunque todavía quedan algunas elementos heredados, el recrecimiento de las parcelas, la concentración y densificación de los pagos vitícolas son evidentes; a todo ello se une la construcción de la bodega (abajo, centro-derecha de la ortofoto de 2007), que ha logrado sumar 350 has a partir de decenas de parcelas de agricultores particulares; y el mismo fenómeno se comprueba en los pagos de alrededor, que han hecho de estas tierras del lecho mayor y terrazas bajas del Duero unos pagos de verdaderas haciendas vitícolas.

En segundo lugar, los cambios tienen una clara incidencia socioeconómica y paisajística. El cultivo del viñedo tradicional era una labor de todos; casi todos los habitantes rurales disponían de alguna viña, porque era necesario aprovisionarse de vino para el año y quien no tenía viñas, debía comprar el vino. Las viñas se trasmitían en herencia y a menudo se dividían y fragmentaban; generalmente se asentaban en los pagos propiamente vitícolas, en los de suelos más arenosos y sueltos, pero también trascendían esos límites, forzados por la necesidad y se extendían por laderas, por el páramo frío y desabrido y dibujaban una imagen de mosaico abigarrado y hasta desordenado, en el que incluso a veces no aparecían ni siquiera los "linios" de vides, porque, antaño, cuando las viñas se cavaban a mano, sin utilizar el ganado para quitar la hierba con el arado, no era necesario alinear las cepas. Sin embargo, 
las replantaciones que se hicieron tras la filoxera estaban ya bien alineadas. Pero, estas estampas terminaron con el éxodo rural, que condenó a los viñedos a subsistir como cultivos del pasado, de poco valor, exigentes en mano de obra que no había y desadaptados a la mecanización que invadió el campo a partir de 1955, y especialmente unos años más tarde.

El proceso de renovación fue general y afectó no sólo a los viñedos del Valle del Duero, de las "riberas durienses", con especial fuerza en las tierras llanas de terrazas y vegas, que fueron destinadas al regadío, por entonces mucho más valorado, sino a todos los viñedos españoles. No obstante, algunas comarcas, menos especializadas y aptas para otros cultivos, resistieron más tiempo y mejor la ola modernizadora, especialmente los viñedos del Bierzo, donde, con más gente y menos tierras llanas, el cultivo de la vid aguantó dos décadas más los envites de la modernización.

b) Los viñedos tintos complementarios y secundarios de Castilla y León: de la marginalidad a la calidad.

Frente a la pujanza de los viñedos durienses, los del Sil han tenido su propia dinámica. Impulsados por la demanda de vinos de calidad, han pasado por las mismas coyunturas que los del Duero, pero sus condiciones de partida eran muy diferentes, ya que, ante todo, arrancaban de un terruño escaso, muy fragmentado y con pendientes excesivas. La pléyade de viticultores, que se unió en las bodegas cooperativas tradicionales, superó esta situación creando algunas bodegas particulares, pero las estructuras básicas de la propiedad y las condiciones de laboreo han dificultado la modernización y expansión. De hecho, tal como se ve en el cuadro 1, el Bierzo ha perdido más de un tercio $(35,7 \%)$ de sus tierras vitícolas, desde antes del ingreso en la CEE hasta hoy, y ello a pesar de las favorables circunstancias de una demanda creciente y solvente y de unas condiciones climáticas propicias para la elaboración de grandes vinos, por lo que, en contra de ese declive general, surgen bodegas y explotaciones dinámicas y expansivas.

La ortoimagen de la figura 5 refleja el paisaje vitícola del Bierzo, donde se mantienen todavía las esencias tradicionales, donde pervive el carácter diminuto de las parcelas y donde se hace difícil organizar una hacienda vitícola a pesar de algunos intentos exitosos como el de Prada y algunos otros bodegueros. La producción de tintos, rosados y blancos dificulta más una clara especialización, que podría hacerse a base de Mencía (para tintos) y de Godello (para blancos)

El Bierzo, con sus 5.250 ha, con sus 55 bodegas adscritas, es una comarca vitícola destacable, pero menor, aunque sus rendimientos son bastante eleva- 
dos, como lo demuestra el hecho de que el Consejo Regulador permite recoger hasta $11.000 \mathrm{~kg} / \mathrm{ha}$ (para la variedad tinta Mencía), por encima de las demás DO, debido sobre todo a un clima suave y lluvioso que rinde generosas cosechas, aunque de menos grado. No obstante, está muy por delante de otros viñedos de vinos tintos regionales, que, aunque tradicionalmente dedicados a la producción de "claretes", hoy han sucumbido a la moda de los tintos; entre éstos se cuentan los de Cigales y los del Arlanza, ya de muy poca superficie, como se aprecia en el CUADRO 1.

Figura 5. Pagos vitícolas de El Bierzo, en Arganza-Canedo (León)

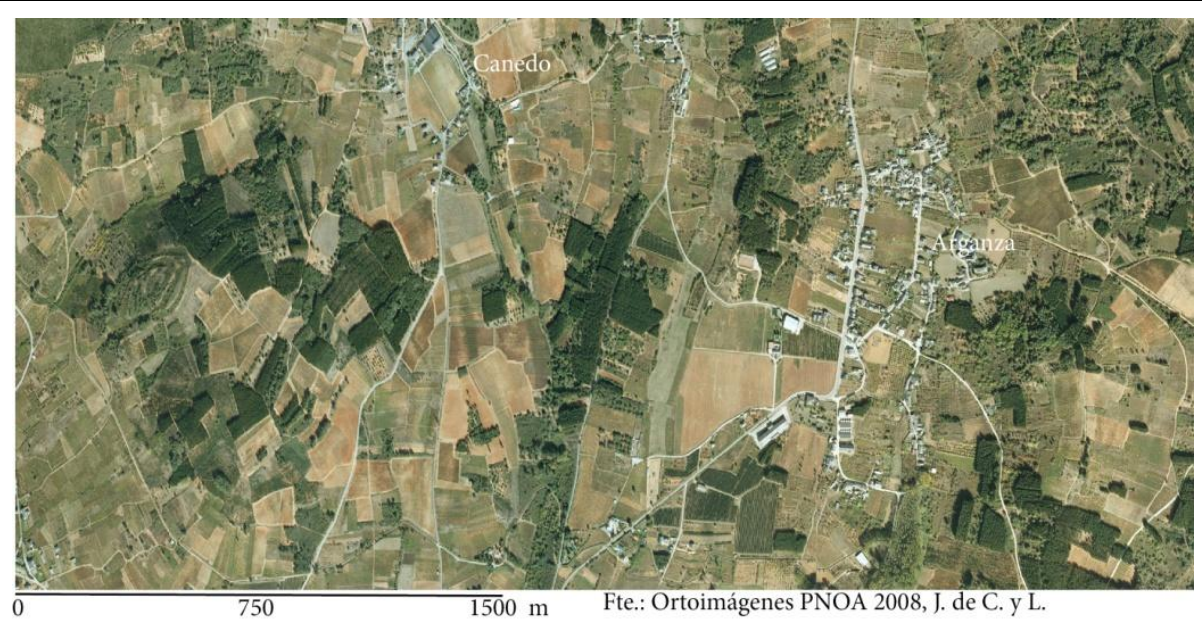

Ortofoto obtenida de PNOA, 2008, proporcionada por la Consejería de Fomento de la Junta de Castilla y León. El acercamiento nos desvela la entidad, fragmentación e irregularidad de las parcelas.

\section{c) Los nuevos viñedos de tinto en comarcas marginales transformadas}

El atractivo de los vinos tintos está invadiendo todas las comarcas productoras, por lo que tanto Cigales como Arlanza han sentido la llamada de la elaboración y crianza de estos caldos; la base de partida es la misma que en el Duero: el Tempranillo, al que se añaden la Garnacha u otras; las condiciones ecológicas son muy parecidas, por lo que la singularidad proviene básicamente de los suelos y de los métodos de cultivo y elaboración y crianza.

En este sentido, Cigales, con sus magras 3.400 ha y Arlanza, con sus 500, no representan grandes comarcas vitícolas, pero sí áreas progresivas. La primera la podemos asimilar a los viñedos durienses, pues, aunque se encuentre en el valle del Pisuerga, cerca de la confluencia con el Duero, realmente tiene continuidad. Paisajísticamente no se diferencia de los viñedos del eje del Duero, por cuanto sigue los mismos pasos; han surgido también 
haciendas vitícolas, con sus bodegas; se mantienen algunos viticultores tradicionales que venden la uva a otras bodegas elaboradoras; progresa la superficie y la modernización, aunque más lentamente que en el eje del Duero y se orientan tanto a los "claretes" tradicionales (los rosados) como a los tintos. Si acaso la variedad Garnacha, con más peso que en el eje duriense, introduce algún matiz. La proximidad a Valladolid, que históricamente supuso un factor de afianzamiento, hoy no le reporta ventaja alguna. La clave de la expansión hacia el futuro estará en la búsqueda del control de la uva y la calidad de los vinos.

En La "Ribera del Arlanza" el proceso es mucho más reciente y, de momento, los viñedos que se han acogido a la Denominación de Origen Protegida (aprobada en 2007), corresponden a antiguos viticultores con vocación de permanencia. Su singularidad está en su localización en unas tierras más altas, pero aún carecen de entidad y de haciendas vitícolas que tiren de la denominación. El paisaje de pequeñas viñas, más o menos concentradas o dispersas, es la característica fundamental.

\section{La pujanza y renovación de los viñedos para vino blanco}

Si los viñedos del eje del Duero son hoy los más afamados y de mayor extensión y valor económico y social de Castilla y León, los de Rueda le siguen en importancia, aunque con caracteres muy distintos. De entrada, se trata de viñedos para vino blanco, que se asientan sobre terrazas y campiñas, alejadas del Valle, con escasa densidad de pies, predominando la espaldera sobre otras formas de implantación y tienen en la variedad autóctona de Verdejo una cepa de gran valor enológico. Su progreso no sólo es incuestionable, sino que incluso es creciente; su pujanza así lo demuestra. No obstante, el hecho de dedicarse a la elaboración de vinos blancos básicamente no favorece el añejamiento, con las consecuentes plusvalías y generación de empleo que le acompañan, pero la calidad indudable de sus vinos está conquistando nuevos consumidores y mercados y, con ellos, ocupa nuevas superficies.

Los vinos blancos de "Rueda" recibieron la primera DO de vinos de Castilla y León, en 1980. Fueron los pioneros y, merced al control de la calidad, triunfaron rápidamente. El Verdejo, como variedad autóctona, no era la más extendida, sino otras como el Jerez Palomino..., que rendían más cantidad de uva y en racimos más grandes, que se vendimiaban mejor, pero esa etapa pasó, por cuanto los pequeños, afrutados y aromáticos racimos de Verdejo están dando un vino que conquista mercados y traspasa fronteras.

Sorprende un poco el vigor de esta comarca vitícola, titubeante entre la 
producción de blancos o la producción de los tres tipos clásicos -blancos, rosados y tintos-, pero, al final, una vez superadas las disensiones, la especialización en los blancos ha conseguido su consolidación y la expansión de los viñedos en grandes pagos, en grandes bodegas y en un conjunto de pequeñas unidades de explotación vitícola familiar con cierto carácter empresarial.

Figura 6. Ortofoto de Rueda (Valladolid) en 1956 (arriba) y en 2007 (abajo)
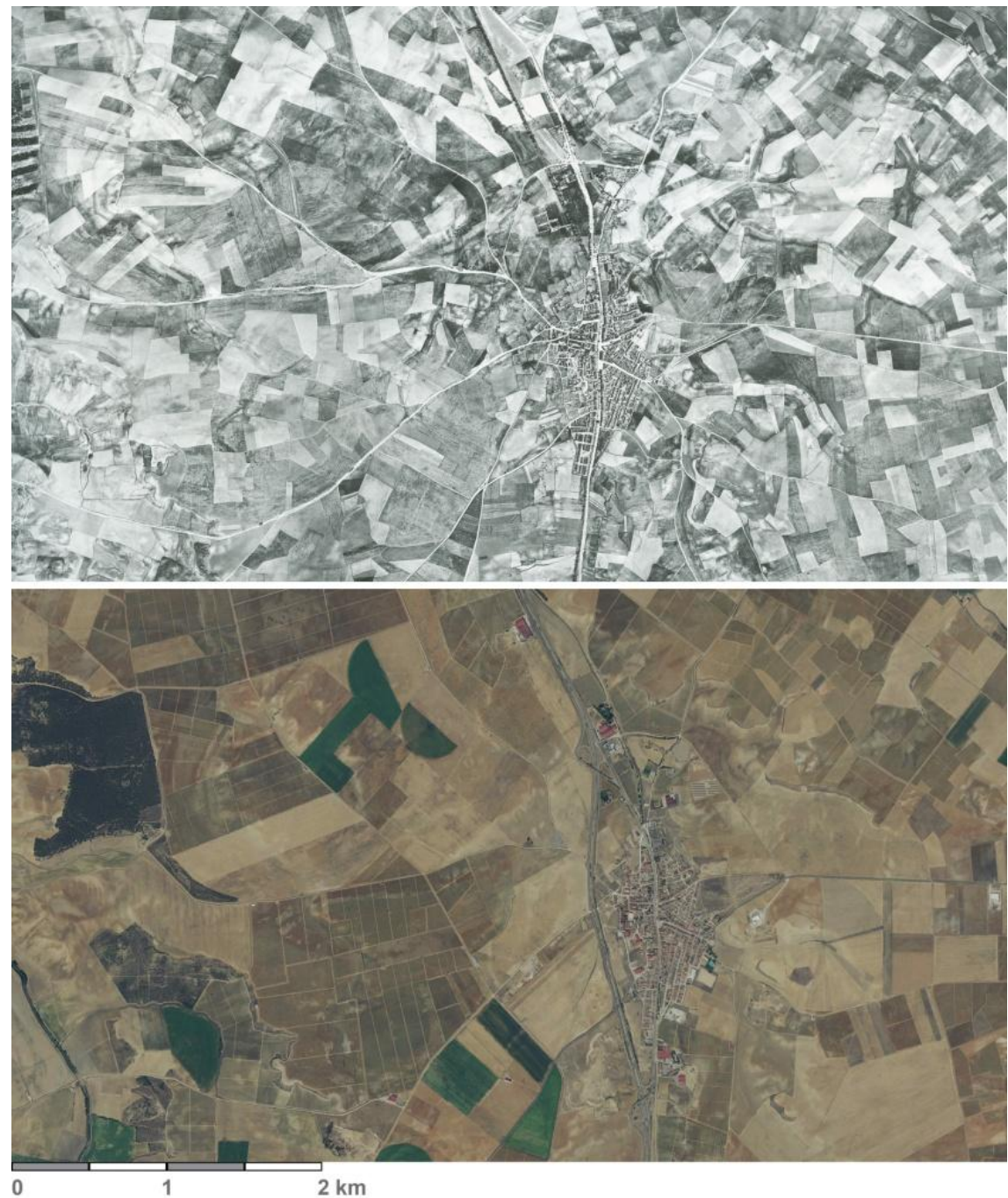

Viñedos de Rueda: se ven las radicales transformaciones del parcelario y llaman especialmente la atención los pagos de viñedo, tipo hacienda vitícola, que quedan al oeste y noroeste del pueblo (a la izquierda del núcleo), en grandes parcelas, con calles bien alineadas y ortogonales 
El paisaje del viñedo de Rueda parte de sus viñas, grandes, ordenadas y en espaldera, que ocupan nuevos terrenos por doquier, como lo ponen de manifiesto las ortofotos de Rueda (FIGURA 6), en las que se ven grandes pagos vitícolas hoy donde en 1956 no había más que campos de cereal.

Sin embargo, la dinámica progresiva y la pujanza de los viñedos comentados hasta ahora contrasta con la ambigüedad, o incluso la pequeñez, orfandad y escaso valor y significado de los viñedos residuales y marginales, que, aunque cuentan con viticultores que intentan subirse al tren de la modernidad y de la calidad, sólo algunos lo consiguen, especialmente en las tierras de viñedos masivos y de gran tradición.

\section{Recuperación y significado de los viñedos tradicionales, residuales y marginales de Castilla y León}

A pesar de la caída en superficie, todos los viñedos restantes han crecido en valor económico, porque la producción de vino es hoy una actividad dinámica, generadora de empleo y rentas muy por encima de lo que sucede con otras producciones agrarias; y ello, pese a la crisis y a que numerosos viticultores familiares sin capacidad de elaboración, viven al albur del precio que quieran pagarles las bodegas elaboradoras. Y si este proceso es general, lo es más en las tierras sin denominación de origen, donde sólo los empresarios con empuje se están abriendo camino con pequeñas y, a veces, grandes bodegas o con otras de tipo hacienda vitícola. Es lo que sucede en la DO Tierra de León, o en áreas de vinos de calidad como los Valles de Benavente o Valtiendas, o en el resto de los pequeños valles vitícolas amparados tan sólo por la denominación genérica de "Vinos de la tierra de Castilla y León", a la cual se han acogido también una decena de grandes bodegas que elaboran excelentes vinos, aunque no integrables en otras DO. De ahí que debemos discriminar las situaciones, porque este "resto de vinos" integra haciendas vitícolas tan destacables como Abadía de Retuerta o Antonio Barceló u otras firmas señeras, que no han podido o querido acogerse a sus denominaciones de origen "naturales" por diversos motivos, frente a comarcas como Cebreros o Sierra de Salamanca, donde el retroceso es la norma, sin que ello signifique minusvalía. El carácter residual y marginal de estas comarcas procede de su pequeñez y no de singularidad o falta de calidad.

En todo caso, la gran DO Tierra de León destaca por su entidad territorial, ya que no por su superficie vitícola. Habiendo sido tradicionalmente asiento de vastos pagos de viñedo, ha retrocedido de manera alarmante. Es esta comarca una de las que más ha sufrido las consecuencias del éxodo rural y de la falta de un proyecto de reconversión. Así, las antiguas tierras de Valdevimbre-Los Oteros, en León, junto al valle del Cea en Valladolid, tan sólo 
Figura 7. Ortofoto de Fresnellino del Monte, cerca de Valdevimbre (León)

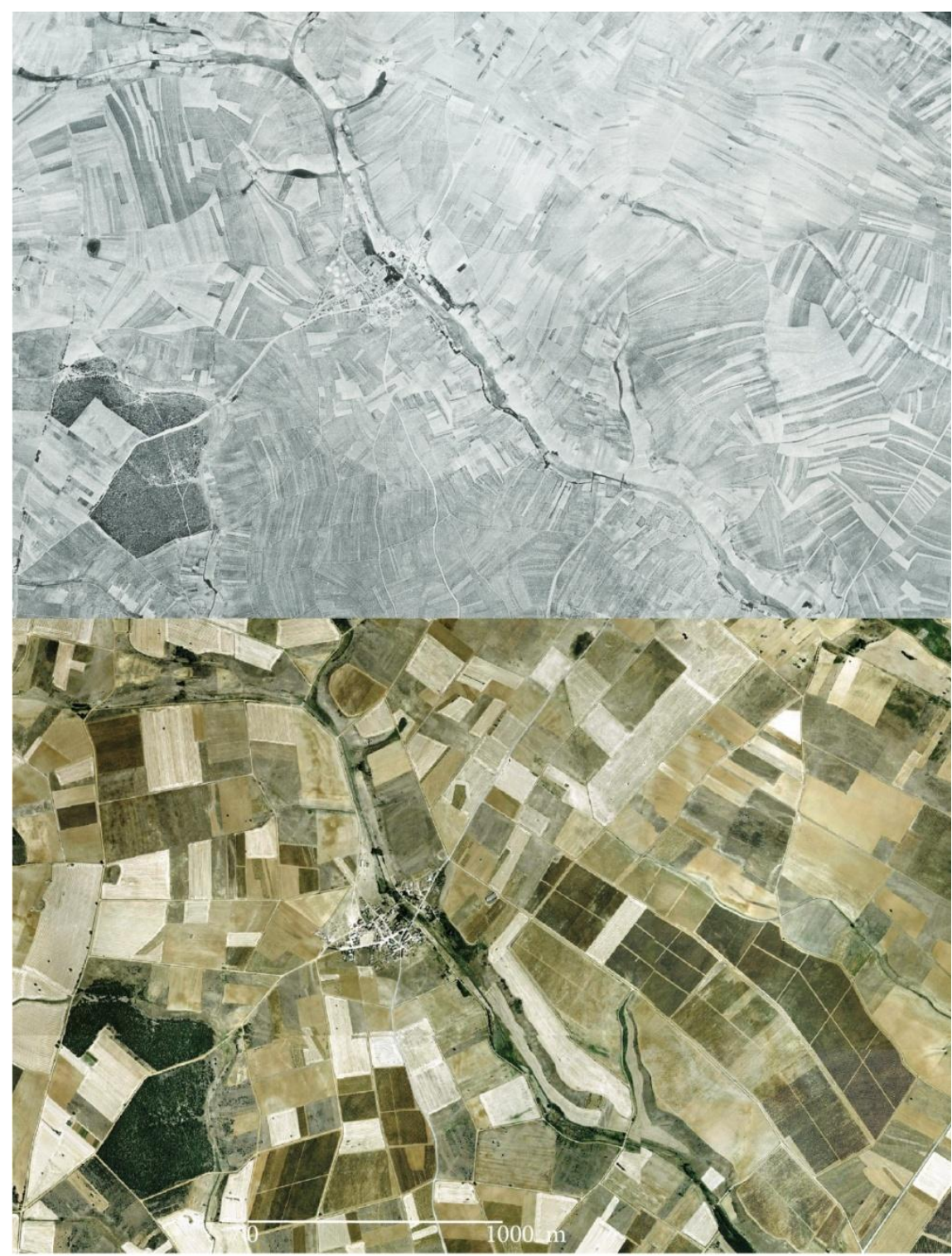

Fresnellino (municipio de Ardón), al sur de la ciudad de León, está en una de las áreas vitícolas más masivas de Castilla y León, que tenía mucho más viñedo que el actual, a mediados del siglo pasado (en 1956, foto superior), aunque todavía lo conserva (en 2008, foto inferior). Se ven aqui también las radicales transformaciones del parcelario y especialmente en los pagos vitícolas del este del pueblo (a la derecha), donde los viñedos tipo "hacienda" han sustituido a cientos de pequeñas viñas familiares. (Fotos aéreas del vuelo americano en 1956 y Ortofoto del PNOA 2008, archivo de la Junta de C. y L.) 
cuentan con 4.500 hectáreas cuando sus páramos y terrazas llegaron a constituir uno de los rincones vitícolas más extensos de la región. La crisis de los viñedos híbridos, que hubo que descepar por prescripción europea, los afectó de lleno. Hoy se han renovado profundamente y siguen los mismos pasos que otras DO consolidadas. Elaboran los tres tipos de vino, partiendo de sus dos cepas tintas autóctonas -Prieto Picudo y Mencía-, junto a otras como el Tempranillo y Garnacha, además del Verdejo y Godello... para blancos. Una singularidad de esta DO es la elaboración de un vino rosado "de aguja" o "madreado", que contiene gas carbónico, con un mercado inseguro y una aceptación ambigua. Ya han aparecido algunas haciendas que elaboran vinos muy cuidados y que han entrado en una dinámica progresiva, aunque en el conjunto queda mucho camino por recorrer.

Otras comarcas vitícolas de la región han sufrido todavía más duramente los efectos del éxodo, de la desvalorización del vino y del retraso en la adaptación a los tiempos modernos y a la demanda del mercado. En esta situación se encuentran los viñedos de Cebreros o los de la Sierra de Salamanca, donde todavía se quiere revertir el signo regresivo de esos viñedos singulares, por más que su localización en tierras de fuertes pendientes y su situación un tanto alejada y de difícil accesibilidad acentúan y contribuyen a su regresión y su declive. Su reducida extensión (aunque Cebreros todavía alcanza casi 3.000 ha) no nos permite dedicarles más que esta mera evocación, en la que ante todo queremos dejar constancia de un paisaje vitícola de crestas y faldas de montaña, generalmente bien soleadas y abrigadas del cierzo. Se trata de viñedos y paisajes relictos, gestionados por viticultores maduros, que se resisten a dejar sus viñas de toda la vida, pero que tampoco se sienten con el vigor necesario para emprender proyectos de futuro, por más que aparezcan algunas iniciativas singulares.

Tanto éstos como los comentados precedentemente constituyen cultivos típicos del agro castellano; totalizan una superficie pequeña, de un 3,8\% de las tierras de cultivo regionales, pero tienen un significado y valor paisajístico y patrimonial que supera con creces su reducido peso en los cultivos regionales.

\section{VALORACIÓN PAISAJÍSTICA Y PATRIMONIAL DEL VIÑE- DO DE CASTILLA Y LEÓN}

Los viñedos de Castilla y León ocupan la menor superficie cuando sus vinos alcanzan el máximo valor y aprecio. Según algunas firmas especializadas en la venta de vinos, los de La Ribera del Duero alcanzan posiciones señeras en el rango de precios de vinos tintos españoles y en la puntuación otorgada por el gran "notario" del vino mundial -Robert Parker- en su revis- 
Figuras 8 y 9. Distribución municipal del viñedo de Castilla y León en 1985 (arriba) y 2008 (abajo)
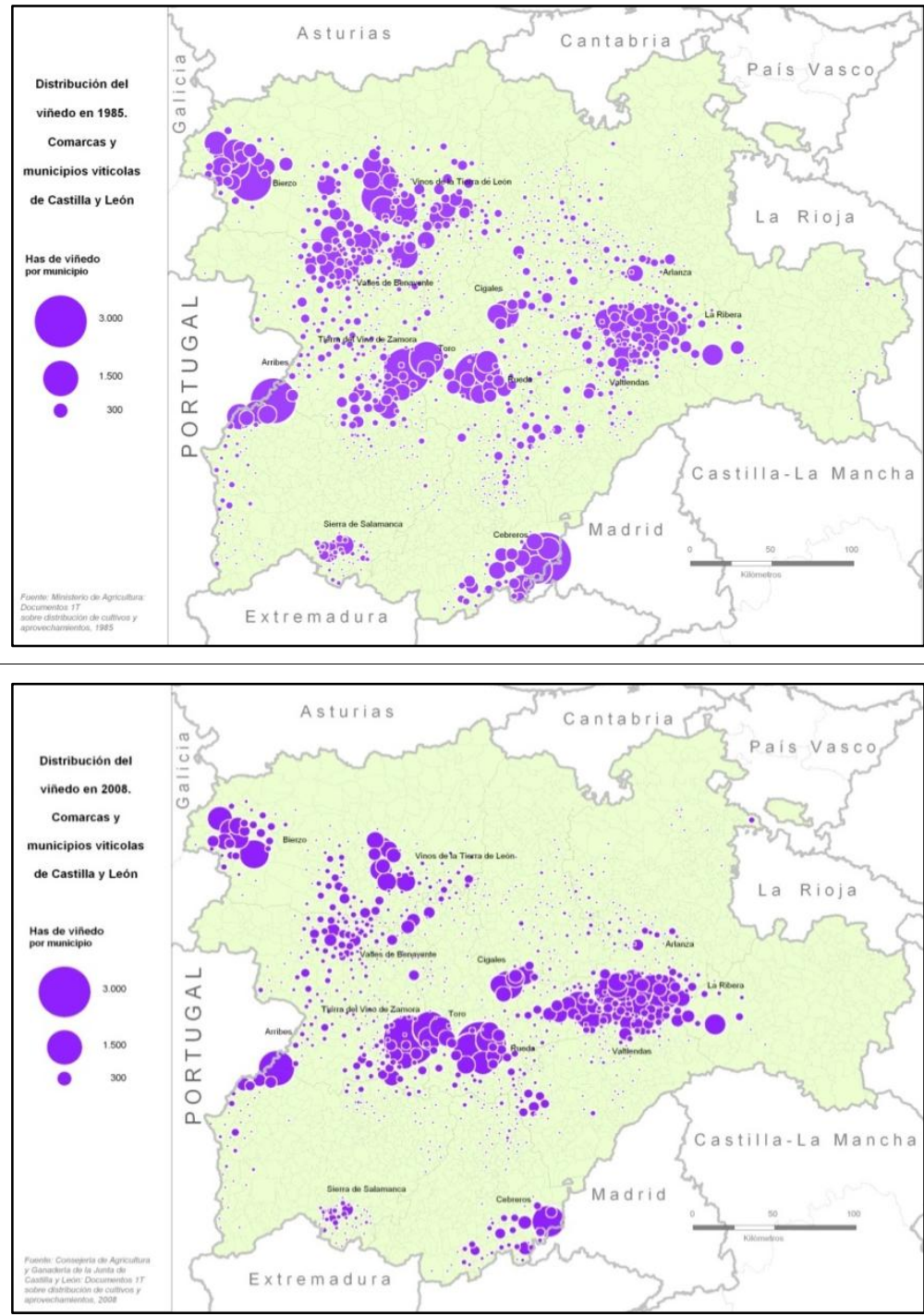

Nótese la pérdida de superficie vitícola entre ambas fechas, a pesar de que en La Ribera y en Rueda ya se observa una nítida recuperación, además de en el municipio de Toro. Las mayores pérdidas se producen en Tierra de León y en El Bierzo, además de en Cebreros, Los Arribes...

N.B. La superficie de los municipios de 1985 se ha adaptado a los que quedan en 2008, sumando las hectáreas de viñedo de los que han desaparecido a aquellos con los que se han fusionado. (Fuente: Documentos IT del MAPA y de la Junta de Castilla y León, Años 1985 y 2008) 
ta The Wine Advocate. No es ocioso recordar que las puntuaciones otorgadas por Parker a los vinos españoles en 2010 llegan a 99 puntos sobre 100 para el Pingus y que los Hermanos Sastre de La Horra o el Vega Sicilia alcanzan 98 puntos y que una decena de los vinos de La Ribera están entre los primeros de España (DIARIO EXPANSIÓN, 2010).

Y es precisamente el valor económico lo que ha provocado el renacimiento del viñedo en Castilla y León, con sus nuevas formas y sus nuevos paisajes. Queda todavía mucho de tradición y de patrimonio, pero lamentablemente no se renueva, porque es evidente que los antiguos barrios de bodegas de cada pueblo han desaparecido o se han reorientado hacia merenderos. Ya no sirven para almacenar y cuidar el vino. Con ellas, se caen los lagares comunales, desaparecen los cuévanos o cestos de mimbre, se pierden los instrumentos de labranza vitícola... Frente a estas pérdidas surgen los nuevos tractores y aperos adaptados al laboreo de las viñas: desde los diminutos "pasquali" (tractores de unos $50 \mathrm{HP}$ ) hasta las vendimiadoras autopropulsadas y hasta las avionetas o helicópteros adaptados a la fumigación del viñedo. Éstas son estampas frecuentes que se ven en las haciendas y pagos vitícolas, construidos sobre antiguas parcelas de viñedo o sobre terrenos nuevos, porque las viñas se están asentando en tierras de "pan llevar", en laderas menospreciadas para todo tipo de cultivos y hasta en páramos frescos o fríos en los que no se había osado implantar cepas. Los nuevos viñedos son colonizadores, con formas muy diferentes a las tradicionales, con fuertes densidades de cepas, con fuertes inversiones para aportar, si son necesarios, dos riegos de apoyo en los veranos secos. Los viñedos han superado a los regadíos en la estima económica de los agricultores, en la generación de empleo y en el valor paisajístico que introducen en los sedientos estíos mediterráneos.

Su valor patrimonial como elementos y factores de ordenación del territorio y de claves del paisaje estival en Castilla y León es incuestionable en las tierras en que se concentran, que incluso se amplían, como vemos en los dos mapas del viñedo municipal en 1985 y 2008 (FIGURAS 8 y 9), en los que se observa, además de una caída casi general, la nueva expansión en La Ribera y en Rueda principalmente y en otras comarcas secundariamente, con la particularidad de que el retroceso de antaño contrasta con el vigor renovado de hogaño; en este sentido, no podemos olvidar que, en una consideración paisajística, lo primero que llama la atención es la superficie, la extensión del viñedo. La superficie actual, de poco más de 71.000 ha, queda aún muy lejos de la que ocupó antes de la filoxera o de la que constata y cartografía Huetz de Lemps en su mapa de los años 1960 (figura 1), pero, a pesar del retroceso y de que todavía está perdiendo extensión en algunas comarcas, está resurgiendo en otras y modificándose para adaptarse a los nuevos tiempos, con las 
espalderas y los goteros como símbolos del cuidado que requieren y la estima que tienen los nuevos viñedos; hechos bien visibles y demostrados en el caso ejemplar del valle del Duero, en su franja central y en las campiñas anejas, como las de Rueda. Los mapas (FIGURAS 8 y 9) evidencian las ganancias de La Ribera, Rueda y Toro, y secundariamente Cigales, frente a las pérdidas del resto de comarcas; aspectos que pueden comprobarse, a su vez en los datos del CUADRO 1.

\section{Los paisajes del viñedo en su medio ecológico}

Los viñedos de Castilla y León, tradicionales o renovados, tienen unas exigencias ecológicas que no se pueden obviar. De entrada, la vid fue siempre considerada como un cultivo secundario o complementario, que ocupaba los peores suelos $\mathrm{y}$, por tanto, se destinaban a viñas las tierras marginales: las guijarrosas, arenosas o las de ladera que no podían dedicarse a los cereales más importantes. Esta exigencia ha cambiado completamente, pues ahora se asientan no sólo sobre terrazas y sobre areniscas y suelos silíceos, sino también sobre suelos de vega y calcáreos. Se busca más la hacienda vitícola, de tamaño adaptado a las necesidades de cada productor, que la calidad reconocida de los suelos para una variedad de uva, pues ésta se subordina al tipo de suelo, buscando siempre implantar el patrón o portainjertos idóneo. El laboreo tradicional del viñedo, guiado por la práctica y la intuición y el saber hacer acumulado durante siglos, ha dado paso al laboreo y viticultura científica, gestionada y dirigida por ingenieros agrónomos y personal especializado. Estos cambios no afectan por igual a los viticultores, pero se están extendiendo de una manera inexorable. De ahí que veamos extensas plantaciones vitícolas en vegas, más o menos húmedas, donde antes nadie ponía vides, pero también vemos trepar las viñas por las cuestas de los páramos, donde antes se habían abandonado incluso los cultivos de cereal, por las dificultades del laboreo mecanizado sobre estas cuestas y por la casi imposibilidad de alimentar a las cepas en terrenos que no eran capaces ni de retener el agua. Estos inconvenientes se salvan mediante el suavizado o alomado de las laderas y mediante un par de riegos de apoyo en junio. Por todo ello, podemos establecer una primera tipificación del paisaje vitícola, en su medio ecológico, en la que cabe distinguir cuatro modelos bien diferenciados. En primer lugar, los viñedos de vega y valle en el Duero, en segundo lugar, los viñedos de abrigo del valle y hoya del Sil, en tercer lugar, los viñedos de campiñas, terrazas y páramos y, finalmente, los de laderas y vertientes montanas.

Los viñedos de vega y valle del Duero son los más modernos, en grandes pagos, ordenados, con sus calles bien delimitadas para poder trabajarlos con las máquinas necesarias. Situados a una altitud de entre 650 y $950 \mathrm{~m}$, configuran un territorio de numerosas haciendas vitícolas, que, superando estas 
franjas bajas de los ríos, se extienden también por terrazas y páramos, pero estos viñedos suelen ser nuevos, por cuanto nunca antes habían ocupado las vegas, aunque sí el "valle" en el sentido amplio del término que utilizan los lugareños, refiriéndose a la hoya y pasillo alargado que labra el Duero sobre las planicies de los páramos, excavando un típico valle en artesa. Estos viñedos, surgidos sobre antiguas tierras de pan llevar, agrupadas mediante operaciones de concentración parcelaria y mediante compra de nuevos inversores a agricultores particulares, salpican todo el valle del río, desde San Esteban de Gormaz en Soria hasta las Arribes en Zamora. No son los únicos, puesto que se acompañan de viñas armadas sobre las herencias del pasado, más alejadas del río, sobre pequeñas terrazas o plataformas de areniscas descubiertas por la erosión de las capas superiores del valle.

Contemplados desde el aire y desde el suelo, son los viñedos más extensos, organizados y densos de la Cuenca, sólo superados en densidad por los del Sil. Las cepas, generalmente en espaldera, forman ejércitos disciplinados de vides, con más de 3.000 pies por hectárea, aunque a medida que nos alejamos del eje del río, encontramos parcelas medias y pequeñas, sueltas, mirando a los cuatro vientos, sin planificación conjunta, como fruto del pasado; esta circunstancia se nota especialmente en el SE de la Ribera, en torno a Fuentelcésped, donde el menudeo de pagos y parcelas vitícolas es la norma. Una buena parte de estos viñedos se asientan sobre las plataformas y campiñas labradas en los bordes de la hoya del Valle, en los que también se han implantado vastos pagos, como los correspondientes a las bodegas Portia en Gumiel de Hizán, los de Torremilanos en Aranda, los de García Carrión (Viña Arnáiz) en Haza, los de Condado de Haza en Roa, los de Cepa 21 en Castrillo de Duero, o los de Dehesa de los Canónigos y Matarromera, Hacienda Abascal o Abadía de Retuerta en el Duero oriental de Valladolid, por no citar Vega Sicilia, que destaca por su solera, u otros como Tinto Pesquera, Protos, Arzuaga... consagrados desde hace años, a los que cabría añadir el más laureado, el Pingus, si no fuera por que tan sólo cuenta con una pequeña extensión de vides, logrando sus caldos a partir de la uva de viñas viejas, comprada a altos precios a pequeños viticultores que mantienen esos viñedos añosos.

A este conjunto podemos asimilar perfectamente el viñedo de Cigales, en el bajo Pisuerga, que, a poca distancia del Duero, goza de los mismos caracteres y, aunque de menor entidad espacial y más atrasado, sigue la senda de los ribereños. Más lejos aparece el del Arlanza, tanto por su escasa entidad -apenas 500 ha- como por su relativo carácter reciente como viñedo de calidad (fue aprobada la DO en 2007), al que no ha afectado aún la onda expansiva. 
Frente a éstos, los viñedos de abrigo de la vega y valle del Sil difieren claramente. Primero, porque la hoya de El Bierzo, aunque tiene un breve relleno sedimentario, es una dovela hundida, a baja altitud, que da escasez de terreno llano y relativa abundancia de vertientes vitícolas de acusada pendiente, situadas entre 400 y 600 m, más cerca del océano y más influida por las borrascas atlánticas -que le proporcionan abundante humedad-, que las tierras del Duero. Los viñedos del Sil son más prietos, más densos, más troceados y repartidos que los del Duero; la parcelación, sin ser extrema, es fuerte y queda poco espacio para las haciendas vitícolas. Baste con decir que las 3.683 hectáreas acogidas a la DOP están repartidas entre 4.210 viticultores asociados, que elaboran los tres tipos de caldo clásicos y que, con la elevada pluviosidad y rendimientos, producen un vino suave, más cercano a las condiciones termo-pluviométricas de Burdeos que a las del Duero. Por otro lado, las tres cuartas partes de los viticultores están adscritos a bodegas cooperativas, que les permiten mantener sus pequeñas parcelas y producciones sin necesidad de transformarse en bodegueros, por lo que la inercia al carácter pequeño y fragmentado de los pagos de viñedo se prolonga en el tiempo.

Los viñedos de campiñas, terrazas y páramos suelen tener carácter colonizador, bien por su reciente ocupación o, en todo caso, porque se han implantado sobre nuevas tierras para modernizarse y superar los problemas de las antiguas parcelas en las áreas en que estaban ya como viñas tradicionales. Afectan principalmente a las campiñas y terrazas de Rueda, a unos 700 a 800 $\mathrm{m}$ de altitud, secundariamente a los bordes septentrionales y meridionales del valle del Duero, bastante más altos, y, finalmente, a las terrazas de la Tierra de León, a una altitud de entre 700 y 850 m, donde tuvieron mucha más entidad que la que ahora tienen. El carácter que une a este grupo es el de la planitud de sus tierras llanas, de horizontes abiertos, y la extensión y concentración de sus pagos vitícolas. Se trata de viñedos de diversa orientación productiva y formas dispares, aunque los tradicionales tenían poca densidad de cepas (menos de 1.100 pies/ha), sobre todo en Rueda, debido a la pobreza de los suelos, pero los que se modernizan suelen implantarse en espaldera, con calles amplias y bien alineadas, a menudo acompañados de dispositivos de riego por goteo y con densidades que doblan a las tradicionales. Tienen poco que ver los de las campiñas y terrazas meridionales del Duero con los del Norte. Los del Sur progresan, se cuidan y se mejoran, los del Norte se mantienen a duras penas; en aquéllos se invierten capitales foráneos y locales, en éstos no ha llegado aún la onda expansiva, por más que se hayan construido algunas bodegas modernas de iniciativas locales y foráneas. 
Los viñedos de laderas y vertientes montanas constituyen, finalmente, el último eslabón de la cadena vitícola de Castilla y León, sobre todo por las dificultades que supone el mantenimiento de sus viñas, localizadas generalmente sobre pendientes de entre 30 y 50 grados, a menudo sobre terrenos abancalados, en estrechas franjas, o en vertientes continuas más extensas, pero de gran dificultad de acceso y de laboreo, y a unas altitudes de entre 700 y más de $1.000 \mathrm{~m}$. Este conjunto está integrado por tres comarcas representativas, como la de Los Arribes del Duero en Zamora y Salamanca, Cebreros en Ávila y la Sierra de Salamanca. La primera, densa, con bancales poco cuidados por el envejecimiento de los viticultores y por el escaso rendimiento económico, se basa en la variedad autóctona Juan García, aunque la bodega Hacienda Unamuno del Marqués de Griñón en Fermoselle ha implantado el Tempranillo (véase figura $10 \mathrm{l}$ y $10 \mathrm{~m}$ ). Los paisajes del viñedo son aquí de lo más espectacular, si bien la dificultad de laboreo los está haciendo retroceder. Algo similar podemos decir de los de la Sierra de Salamanca (FIGURA 10j) o de los de Cebreros, como viñedos montanos, en vertientes solanas, aprovechando rellanos, construyendo bancales y creciendo cara al sol, en suelos arenosos y cálidos que prestan buenas cualidades a sus caldos, pero dificultan la mecanización y frenan las iniciativas empresariales, por lo que retroceden inexorablemente.

Algunos viñedos de calidad, como los Valles de Benavente o los de Valtiendas se asimilan a los de las comarcas vecinas. Así, los primeros siguen la misma dinámica que los de la Tierra de León y los de Valtiendas se parecen a los de La Ribera del Duero, pero siempre añaden alguna singularidad, como la mayor altitud o la fragmentación, la falta de iniciativas..., que empecen su mejora.

Con este panorama, no podemos olvidar que la vid es un cultivo de excepcional valor paisajístico, que, además, aporta mayores rendimientos económicos y más empleo que otros aprovechamientos, a lo que suma un legado patrimonial considerable, no sólo por las construcciones de lagares, bodegas..., sino incluso por las propias cepas, algunas de las cuales son octogenarias y nonagenarias, contribuyendo por sí mismas a aumentar el valor paisajístico del viñedo, por sus troncos retorcidos, de consistencia arbórea, por su estampa singular en pagos de viñedos históricos (véase FIGURA 10k). Pero el valor paisajístico propio del viñedo aumenta y se diversifica de acuerdo con la organización y la dinámica económica de las viñas y de las bodegas que las sostienen, que se superponen al entramado físico.

\section{Los paisajes del viñedo en su medio económico y social}

De entrada y, como venimos insistiendo, el paisaje del viñedo actual di- 
fiere sensiblemente del histórico. Hoy, con menos extensión de viñas, se producen más y mejores vinos y, a pesar del retroceso y pérdida de superficie vitícola en algunas comarcas, las que han apostado por la calidad están claramente en progreso. Este avance, de todos modos, no se configura como en el pasado, con un sinfín de pequeños propietarios/viticultores, sino que se especializa fuertemente y se adapta a la demanda de un mercado solvente y exigente. Por ello, no sólo está creciendo la superficie vitícola, frente al retroceso que tuvo lugar durante los años 1970 a 1990, sino que, al calor de las nuevas viñas, surgen las nuevas bodegas, tanto de talla familiar como empresarial y, con las nuevas bodegas, se expande la cultura del vino y progresa el turismo en torno a su crianza y consumo, lo que, a su vez, potencia el viñedo. De este modo, el eje del Duero y algunas otras tierras vitícolas regionales están conociendo un resurgimiento imparable, aunque todavía se mantienen pagos vitícolas tradicionales organizados a la antigua usanza y sostenidos por bodegas cooperativas, que recogen y transforman la uva de sus socios, lo mismo pasa en El Bierzo o en otras comarcas, y, junto a ellas, se expande con fuerza la "hacienda vitícola", que se erige como la nueva explotación, con su bodega y a menudo con dependencias anejas para hacer frente a la demanda de los turistas del vino. Éstas son las claves de los paisajes vitícolas y vinícolas de Castilla y León, a las que se suma la del legado histórico, la de los viñedos en manos de viticultores resistentes tan sólo por amor a las viñas y su cultura, pero que, si en unos casos se orientan a la construcción de nuevas bodegas, apoyados y animados por sus familiares, en otros lo abandonan cuando llega su ruina vital. Todos estos avatares merecen una consideración.

\section{a) El paisaje expansivo y la dinámica de la hacienda vitícola}

Ha quedado claramente expuesto y comentado que este tipo de explotación, sin ser nuevo en la región, se ha expandido a partir de los años 1980, cuando se ponen en marcha las DO y cuando se apuesta claramente por la calidad. Lo primero que llama la atención es el fenómeno expansivo de este tipo de explotación de viñas y crianza de vinos, que obedece tanto a iniciativas internas como a inversiones externas. La pujanza de Rueda y La Ribera se extendió por toda la región y sirvió de ejemplo de lo que se podía conseguir en el mundo del vino. Así, la hacienda vitícola, con su bodega, ha cundido de una manera general y ha hecho subir a los vinos de Castilla y León a puestos eminentes y señeros en el panorama vínico mundial.

La hacienda ha penetrado con fuerza inusitada por todo el eje duriense y ha irradiado al resto de la región. Se caracteriza ante todo por una explotación vitícola de dimensiones medias y grandes, de entre unas 30 a 300-400 ha, distribuidas en pagos ordenados, con linios paralelos, con calles anchas y bien trazadas para que puedan pasar las máquinas, con densidades de cepas 
que superan los 3.000 pies/ha, ..., en suma, una plantación de viñedo con todo los elementos característicos, aunque huelga decir que, en contra de lo que sucedía en las antiguas plantaciones tropicales, carece de viviendas para los obreros, los cuales moran en los pueblos vecinos y se desplazan desde ellos al tajo, si bien durante la vendimia reciben a obreros forasteros, que pasan entre 10 y 15 a 20 días cortando y triando racimos.

Las cepas aparecen organizadas en espalderas bajas, por más que algunas explotaciones prefieren la vid en copa, que era la forma tradicional. La espaldera tiene la ventaja de la aireación y el soleamiento del racimo y la mayor cantidad de fruto; la copa o vaso, la de una maduración menos repentina y más cuidada, sin soles excesivos que rebajan la cantidad de antocianos en la piel de la uva; aquéllas sirven para una vendimia mecanizada, como se hace en Rueda, donde la máquina recoge 4 de cada 5 hectáreas plantadas, ésta exige una vendimia manual, a menudo selectiva y, por tanto, más abocada a la calidad del fruto y del vino. Frente a Rueda, en La Ribera se vendimia casi todo manualmente, a pesar de que las espalderas predominan en casi todas las haciendas vitícolas, para favorecer la poda mecánica, el riego si se necesita u otras labores.

La bodega suele acompañar a las parcelas de viñedo, en medio del campo, con unas instalaciones singulares en las que se cuida mucho el aspecto, tanto que algunos edificios han sido diseñados por prestigiosos arquitectos como Richard Rogers o Norman Foster, responsables de las bodegas Protos de Peñafiel y de Portia en Gumiel de Hizán respectivamente. Esta arquitectura vanguardista, u otra más tradicional pero muy cuidada, como la de Abadía de Retuerta, son producto del gusto por lo estético y de la siembra de un nuevo atractivo: el turismo en torno al vino; en todos estos aspectos, las haciendas han hecho un gran esfuerzo e inversión, de modo que una gran parte de las haciendas vitícolas de Castilla y León tienen restaurantes, hoteles, salas de catas y otras dependencias aptas para el enoturista. En las fotos (FIGURAS 10a, 10b y 10c) se pueden apreciar claramente los rasgos comentados, definidores del carácter de las haciendas, tanto en La Ribera como en Toro)

Aunque la hacienda vitícola destaca con fuerza por encima de otras formas de organización y explotación, son bastante frecuentes las bodegas de talla familiar, que responden al mismo tipo, circunstancias y dinámica, aunque suelen pertenecer a capitales autóctonos, montadas por viticultores locales, que disponen de viñas o compran tierras para implantarlas y que suelen tener unas dimensiones reducidas, de entre 20 y 40 has. Este tipo de explotación es frecuente; a menudo construye la bodega en el propio núcleo de población o a veces en medio del solar vitícola. Si el origen y las dimensiones son distin- 
Figura 10. Paisajes vitícolas de Castilla y León
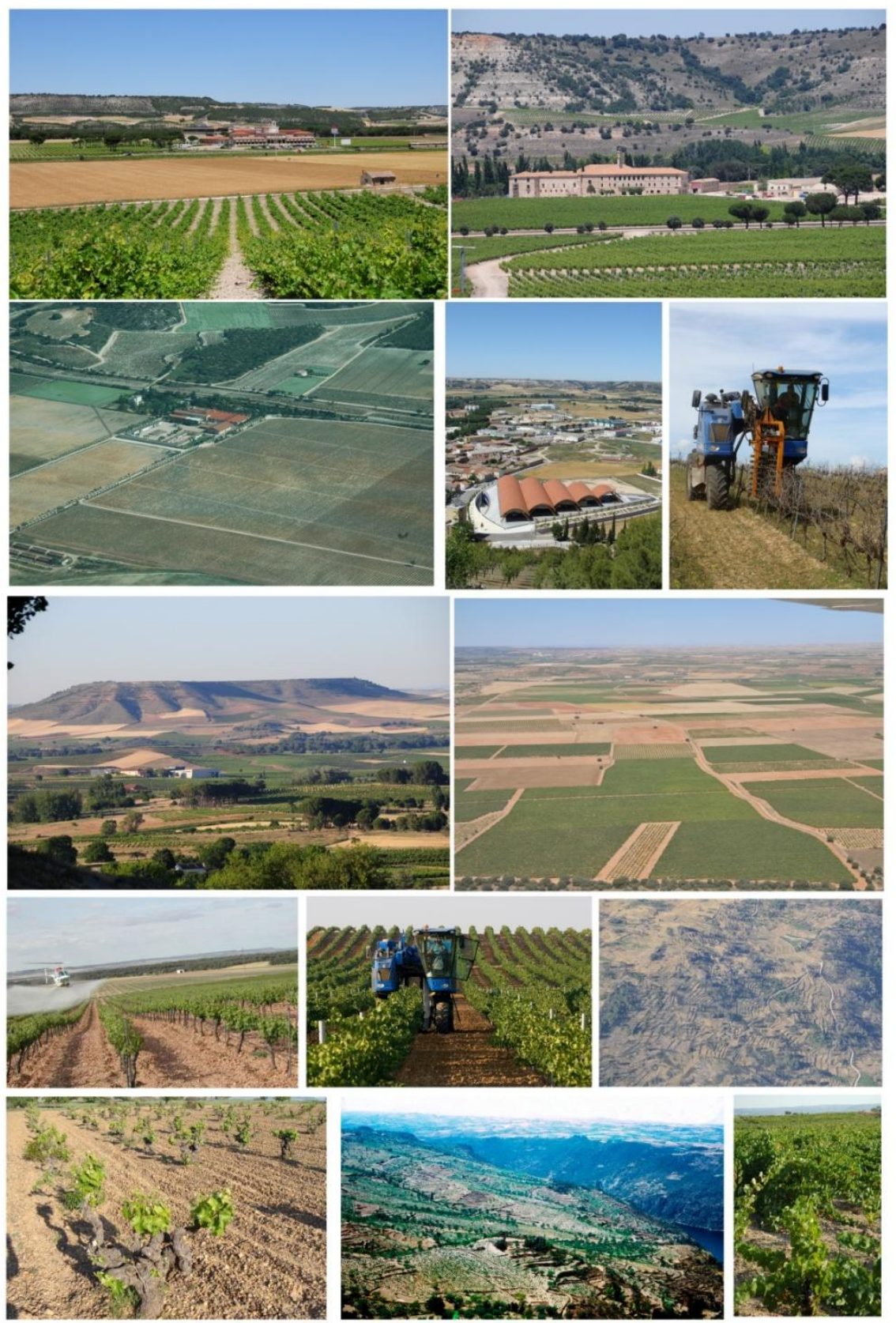

Fotos ordenadas de izquierda a derecha y de arriba abajo: 10a-Viñedo de hacienda vitícola (Arzuaga en La Ribera del Duero); viñedo colonizador en el lecho mayor del río (vega) y 
bordes, con los edificios que incluyen restaurante y hotel de 5 estrellas; 10b-Hacienda vitícola Abadía de Retuerta, con el edificio convertido en hotel de lujo, la bodega (no visible en la foto) se encuentra próxima. Las viñas colonizan la vega y trepan por las laderas; 10cBodegas Vega Sicilia en Olivares de Duero, buque insignia de La Ribera; 10d-Bodega Protos, antigua cooperativa, convertida en S.A., diseño de Richard Rogers en la villa de Peñafiel, Ribera del Duero; 10e-Prepoda mecánica en una hacienda vitícola en Mucientes (DO Cigales); 10f- Pago de viñedo mixto, de cooperativa y de bodega familiar, en el Cerro de Manvirgo (Ribera del Duero); $10 \mathrm{~g}$-Viñedo de pago vitícola de Toro. Mezcla de aprovechamientos, viñas tradicionales de parcelas relativamente grandes, con distinta orientación; $10 \mathrm{~h}$ y 10iLabores de fumigado con helicóptero y de vendimia con vendimiadora mecánica en Rueda (Foto: M. Esteban de Íscar, 2007); 10j-Bancales de viñedo de la Sierra de Salamanca (Foto E. Baraja, 2010); 10k-Viñedo en copa, de viña vieja en un pago vitícola de Fuensaldaña (Cigales); 101 y 10m-Los Arribes del Duero en 1972 (a la izquierda) y en el borde de la penillanura en Fermoselle (a la derecha). (Las fotos en las que no se cita autor han sido tomadas por C. Cascos y F. Molinero)

tas, la dinámica y resultados corren parejos, al calor de la demanda de vinos de calidad que ha modificado el mercado. Sostenidas por una mano de obra familiar más o menos abundante, y complementada por algún obrero fijo más otros eventuales, se extienden por toda la región.

b) El paisaje y dinámica de los viñedos heredados y gestionados por cooperativas: viñas dispersas y pagos de viñedo

Las bodegas cooperativas, que surgieron como tabla de salvación de los viñedos y vinos en los años 1950 y 1960, cumplieron un papel esencial en el mantenimiento de la vid y la producción de vino durante ese período, merced a la homogeneización de los caldos, pero fueron sucumbiendo posteriormente ante los arranques generalizados de viñas, que las dejaron sin mercancía. Su situación se hizo tan insostenible que algunas fueron vendidas al mejor postor en los años 1980 y 1990. Esos edificios grandes, con estilo impersonal de nave agrícola y fachada arqueada, fueron capaces de mantener durante dos décadas los viñedos de numerosos pequeños viticultores, que, al emigrar o envejecer, dejaron de entregar uvas, lo que unido al mal precio del vino, colapsó su funcionamiento. Sin embargo, algunas resistieron y se acogieron al boom de las DO, se remozaron y lograron enderezar el rumbo de decaimiento vitícola. El Bierzo es un buen ejemplo de esta situación, pero en La Ribera, donde casi todos los municipios cuentan con una, llegaron a venderse algunas bodegas cooperativas por incapacidad de mantenerse operativas.

Merced a estas bodegas se ha mantenido el paisaje vitícola tradicional (FIGURA 10f, cerro Manvirgo), fragmentado, con numerosos propietarios/viticultores que se adaptan a un mercado exigente mediante la renovación del viñedo, su organización en espaldera, su cuidado intensivo y la gestión del comercio vitícola de una manera más profesional, con personal especializado, aunque es en este capítulo donde más retrasadas andan. Por ello, algu- 
nos viticultores dinámicos han abandonado la organización cooperativa para montar su propia bodega de talla familiar, que, con una treintena de hectáreas, les permite emprender una nueva aventura, manteniendo sus antiguas viñas o renovándose y construyendo su propia explotación vitícola y bodega. Ha sido una evolución muy frecuente en La Ribera, pero también se está dando el fenómeno inverso en Rueda, donde un grupo de viticultores que vendía uva a las haciendas rodenses, se ha unido para construir su propia bodega y comercializar sus caldos, debido a las distorsiones comerciales y a la inseguridad de venta de la uva, provocadas por la crisis económica de 2008/2009. En todo caso, algunas potentes cooperativas, como la comarcal de Cuatro Rayas en La Seca, han sido capaces de sortear todos los obstáculos y mantener una organización pujante y hasta boyante, que ha favorecido la dinámica expansiva de los viñedos rodenses, sostenidos por tres centenares de socios que producen 11 millones de kilos de uva sobre unas 2.100 ha.

La ambivalencia de las bodegas cooperativas no ha impedido el mantenimiento de una pléyade de modestos viticultores, que a caballo de la buena venta de los caldos regionales, han mantenido, reformado o ampliado sus viñas, bien en los pagos tradicionales, bien en tierras cerealistas. Sin embargo, queda todavía en Castilla y León un elevado número de viticultores que ni pertenece a cooperativas ni tiene bodega propia, por lo que vende la uva a quien puede y como puede.

\section{c) La fragmentación de las viñas de pago y la adaptación a las coyunturas}

En efecto, dadas las exigencias de calidad actuales, todos se han esforzado en conseguir buena uva, bien madura, sana, con elevado grado y contenido de antocianos (en las variedades tintas) y diversa en aromas florales. Este objetivo se ha visto frenado por la crisis económica, que ha perjudicado especialmente a los viticultores dependientes de bodegueros que se niegan a comprarles la uva por mor de la disminución de las ventas, hecho que está causando desorientación y desánimo, que en circunstancias extremas acaba en abandonos; pero entre tanto, queda todavía un elevado contingente de pequeños viticultores, tanto en las comarcas vitícolas con DOP como en otras aledañas o en las que carecen de figura de protección, que mantienen sus viñas de pago, es decir, aquellas que se agrupan sobre antiguos pagos vitícolas que no se han arrancado.

En este tipo se incluyen los viñedos de Arribes, Cebreros, los de la Sierra de Salamanca (FIGURAS 10l, 10m y 10j), algunos pagos de los Valles de Benavente y determinados sectores y pagos vitícolas de cualquier otro territorio regional (FIGURA 10k). En gran medida, se trata de viñedos perdedores, en los que no hay iniciativas aglutinadoras para dar el salto a la calidad, salvo 
en contados casos que mantienen encendida la esperanza. Por su heterogeneidad, no podemos hacer una caracterización para todos ellos, pero sí podemos decir que los une su rasgo común de "viñedos de pago vitícola", de tierras marginales que tradicionalmente sólo servían para el viñedo. Suelen localizarse en los valles de los ríos, sobre sus terrazas o suelos de gravas y arenas, o en las vertientes montanas. Asimismo, están hechos de retazos, de pequeñas parcelas heredadas de la época de la agricultura tradicional en que la presión sobre la tierra era muy fuerte. Se orientan a vinos de la tierra, desde el "clarete" al "ojo de gallo" -tinto de poca capa-, al blanco aromático...; suelen estar trabajados por agricultores de edades provectas. Si logran superar estos años de crisis, es posible que entren en una nueva ola expansiva que ha de sobrevenir al marasmo actual, pero entretanto, forman pagos vitícolas menguantes y aminorados, cuyo futuro está en el aire.

\section{CONCLUSIÓN: LOS PAISAJES VITÍCOLAS DE LA HACIEN- DA, LA BODEGA FAMILIAR Y LOS VIÑEDOS DE PAGO}

Los viñedos y vinos de Castilla y León están recorriendo un camino de éxitos que nunca antes habían conocido. Su pujanza arranca de la demanda solvente de vinos de calidad, que los viticultores regionales han aprovechado para responder satisfactoriamente, merced a unas condiciones ecológicas favorables, a una cuidada producción de uva y a una esmerada elaboración de vinos. Sin embargo, la superficie vitícola, que está empezando a crecer, lleva decenios de pérdidas, que pueden verse incrementadas circunstancialmente por la crisis económica de 2008/2011. Cuando esta pase, probablemente, los viñedos y vinos de Castilla y León volverán a recuperar terreno y a aproximarse a la extensión que tuvieron en los años 1950 e incluso a la de finales del siglo XIX, cuando todavía no habían sido atacados por la filoxera. Pero este proceso exige tiempo, además de la búsqueda y compra de derechos de plantación, si no desaparecen en 2015.

En nuestros días el viñedo configura un paisaje singular, de gran valor, que responde básicamente al tipo de explotación que lo genera y al medio ecológico en el que se encuentra. Los viñedos del eje del Duero están teniendo una proyección y expansión extraordinarias, basadas en la calidad de sus vinos tintos, de fama mundial. Indudablemente van a más. Lo mismo sucede con los blancos de Rueda en las campiñas meridionales del Duero, pero incluso otros vinos muy distintos como los de El Bierzo están conquistando mercados y ganando elevadas puntuaciones de Parker.

La cotización de los vinos de Castilla y León ha favorecido la cristalización de tres grandes tipos de explotaciones y paisajes vitícolas: la hacienda, la bodega familiar y el viñedo de pago, a los que se suman otras formas sin- 
gulares. La hacienda vitícola está extendiéndose como la forma más racional y favorable para la producción de grandes vinos en Castilla y León. Es el presente y el futuro de estas tierras, como hemos visto. Dada su entidad y su progreso es la forma de organización que imprime carácter y crea paisaje; en todas las comarcas vitícolas destaca nítidamente por la magnitud y el orden de los elementos, bien sea sobre valles, terrazas, campiñas alomadas, páramos e incluso sobre cuestas y vertientes con elevada pendiente, pero no es la única explotación ni forma de paisaje vitícola. A la hacienda le acompaña la bodega familiar, que se nutre de los viñedos de pago en unos casos y de sus propias viñas en coto redondo, en otros; tiene dimensiones pequeñas y medias, pero significativas, en torno a unas 30 ha; va a más y está muy extendida; a menudo, cuando triunfa, da el salto hacia la hacienda vitícola y construye una nueva bodega en medio de una de sus parcelas grandes; es el segundo elemento de caracterización paisajística del viñedo regional. El tercero, y de gran entidad espacial, son los pagos de viñedo, tradicionales y nuevos, sostenidos por viticultores sin bodega y por cooperativas; se trata de tierras aptas para el cultivo de la vid, sobre suelos calientes, a menudo guijarrosos, arenosos o areniscosos, que tradicionalmente se dedicaron a la vid y hoy han perdido una gran parte de este cultivo, aunque todavía se mantienen con abundantes viñas. Estas plantaciones pertenecen principalmente a viticultores socios de cooperativas y, secundariamente, a bodegas familiares o a particulares; en unos casos avanzan y en otros retroceden; cuando pierden superficie vitícola, se van degradando y se convierten en terrenos de viñas sueltas y dispersas, que completan el panorama y el paisaje vitícola regional. Obviamente, la hacienda vitícola, de talla familiar o empresarial se impone sobre los demás y muestra el camino a seguir.

\section{BIBLIOGRAFÍA Y FUENTES}

BARBA, L. M. (2003): Ribera del Duero. Vinos de España. Barcelona, Bon Vivant, $136 \mathrm{pp}$.

BöHM, Jorge (2010): O Grande Livro das Castas. Portugal Viticola. (Enciclopedia dos Vinhos de Portugal). Lisboa, Chaves Ferreira, $2^{\mathrm{a}}$ ed. 230 pp.

Casanova Todolí, U. De ( ): Paseo por las Comarcas Vinícolas de Castilla y León. Consejería de Educación y Cultura de la Junta de Castilla y León, 192 pp.

Casanova Todolí, U. De (1994): Diccionario del Vino de Castilla y León. Ediciones Amarú, $248 \mathrm{pp}$.

CLC (2006): http://www.eea.europa.eu/data-and-maps/data/clc-2006-vector-dataversion Clase de viñedos para toda la UE.

Consejería De Agricultura de la JunTa de CASTILla y León (2010): Documentos 1-T sobre Distribución de Cultivos y Aprovechamientos en el término municipal, Año 2008 
Diario Expansión (2010): Valoración de los vinos españoles puntuados por Parker en el año anterior, en http://www.expansion.com/2010/04/29/empresas/ $\underline{1272567551 . h t m l)}$

ENODESTINO (2010): «Ruta del vino», Bodegas propuestas en La Ribera, en http://www.enodestino.com/ruta-vino-ribera-duero_do_230,0.html

García DEL Río, F. (2001): Ribera del Duero. Vinos y bodegas, Madrid, Alianza Editorial, $200 \mathrm{pp}$.

GIRARD-LAGORCE, S. (2006): Los mejores vinos del mundo. Barcelona, Ediciones Universitarias, $383 \mathrm{pp}$.

Hidalgo, L. (2002): Tratado de viticultura general. Madrid, Mundi Prensa, $3^{\text {a }}$ ed., $1.235 \mathrm{pp}$.

http://www.bodega-privada.com/blog/?p=693 Puntuaciones Parker 2010 de vinos españoles (edición The Wine Advocate 2010)

http://cyl.nortecastilla.es/vinosybodegas/bloquetexto.cfm?portal=570\&seccion=108

$\underline{0}$ (Web del Norte de Castilla, gestionada por Javier Pérez Andrés, con información de todas las D.O. P. de vinos de Castilla y León)

HuETZ DE LEMPS, A. (1967): Vignobles et vins du Nord-Ouest de l'Espagne. Bordeaux, Institut de Géographie. Faculté de Lettres Bordeaux, 2 vols., 1005 pp.

Huetz DE LEMPS, A. (2005): Viñedos y vinos de Castilla y León. Segovia, Consejería de Agricultura y Ganadería de la Junta de Castillas y León - Fundación castellanoleonesa para la cultura del vino, $683 \mathrm{pp}$.

Iglesia Berzosa, J. y Villahoz GarcíA, A. (1982): Viñedo, vino y bodegas en la historia de Aranda de Duero, Aranda de Duero, Ayuntamiento de Aranda de Duero, 203 pp.

MAPA (2009): http://www.mapa.es/alimentacion/pags/consumo/año_movil_jul07jun08/fichas consumo.pdf (Panel alimentario del M.A.P.A- Fichas de Consumo Alimentario. Año móvil Julio 2007 - junio 2008) (Consulta del 15 de junio de 2009)

MARm (2010): Panel alimentario del M.A.P.A- Fichas de Consumo Alimentario. Año móvil Julio 2007 - junio 2008): http://www.mapa.es/alimentacion/pags/ consumo/ año movil_jul07-jun08/ fichas consumo.pdf (Consulta del 28/ 10/2010)

MARM (2010): Consumo Alimentario en España, (p. 26 de la presentación), consultable en: http://www.mapa.es/alimentacion/pags/consumo/ año_movil_jul08 jun09/año_movil_jul08_jun09.pdf

MARTín RodRÍGUEZ, M. Á. y VIDAL GIMÉNEZ, F. (2004): «La nueva ley de la viña y del vino: líneas maestras y consecuencias para las actuales denominaciones», en Estudios Agrosociales y Pesqueros, n $204,47-66$.

MARTínEZ DE TODA FERNÁNDEZ, F. (2011): Claves de la viticultura de calidad. Nuevas técnicas de estimación y control de la calidad de la uva en el viñedo. Madrid, $2^{\text {a }}$ ed. Mundi Prensa, 253 pp. ( $1^{\text {a }}$ ed. 2008)

Ministerio De Agricultura (1987): Documentos 1-T sobre Distribución de Cultivos y Aprovechamientos en el término municipal, Año 1985, para todos los municipios de España. 
MOLINERO HERnANDO, F. (1979): La Tierra de Roa: la crisis de una comarca vitícola tradicional. Valladolid, Departamento de Geografía, Universidad de Valladolid, $343 \mathrm{pp}$.

Molinero Hernando, F. (1997): «La Ribera del Duero. Transformaciones y dinamismo de una comarca vitícola», en Medio Ambiente en Castilla y León, $\mathrm{n}^{\circ} 7$, pp. 19 a 35.

Montoya García ReOl, E. (2006): La Ribera del Duero burgalesa. El vino y su denominación de origen. Burgos, Diputación de Burgos, 317 pp.

Páginas web de todas y cada una de las D.O. P. (2010), con informaciones clave respecto a la superficie, rendimientos, variedades, bodegas, viticultores, marcas, historia...

PARKER, R. (2006): Los mejores viñedos y bodegas del mundo: una perspectiva moderna. Barcelona, Grafos, 708 pp.

Pi ERRE (2010): Guía Peñín de los vinos de España 2011. Madrid, Grupo Peñín (www.grupopenin.com).

SERVEIS DE COMUNICACIÓ EMPRESARIAL 1.060 (2006): Suplemento anual: Denominación de Origen y Productos de Alta Calidad. http://comunicacionempresarial. net/ADMIN/upload/comempresarial014.pdf (Consulta de marzo de 2010)

VICENTE ELÍAS, L. (2011): El paisaje del viñedo. Una mirada desde la antropología. Madrid, Edit. Eumedia, 336 pp.

VV.AA. (2008): Guía del turismo del vino en España 2009. Madrid, Anaya, 918 pp. 